\title{
Reviews
}

\section{Nanocrystalline Semiconductors: Synthesis, Properties, and Perspectives}

\author{
Tito Trindade* \\ Department of Chemistry, University of Aveiro, 3810 Averro, Portugal \\ Paul O'Brien*,† and Nigel L. Pickett \\ Department of Chemistry and The Manchester Materials Science Centre, \\ University of Manchester, Oxford Road, Manchester, M35 9PL U.K. \\ Received October 24, 2000. Revised Manuscript Received May 8, 2001
}

\begin{abstract}
The synthesis and study of so-called "nanoparticles", particles with diameters in the range of 1-20 nm, has become a major interdisciplinary area of research over the past 10 years. Semiconductor nanoparticles promise to play a major role in several new technologies. The intense interest in this area derives from their unique chemical and electronic properties, which gives rise to their potential use in the fields of nonlinear optics, luminescence, electronics, catalysis, solar energy conversion, and optoelectronics, as well as other areas. The small dimensions of these particles result in different physical properties from those observed in the corresponding macrocrystalline, "bulk", material. As particle sizes become smaller, the ratio of surface atoms to those in the interior increase, leading to the surface properties playing an important role in the properties of the material. Semiconductor nanoparticles also exhibit a change in their electronic properties relative to that of the bulk material; as the size of the solid becomes smaller, the band gap becomes larger. This allows chemists and material scientists the unique opportunity to change the el ectronic and chemical properties of a material simply by controlling its particle size. Research has already led to the fabrication of a number of devices. This review aims to highlight recent advances in the synthesis of compound semi conductor nanoparticle materials and their potential use in areas such as catalysis and electronic device fabrication.
\end{abstract}

\section{Introduction}

Recently there has been substantial interest in the preparation and characterization of materials consisting of particles with dimensions in the order of a few nanometers so-called "nanocrystalline materials". ${ }^{1-8}$ The aim of this article is to overview and highlight recent work in this area. One factor driving current interest in nanoparticle research is the perceived need for the further miniaturization of both optical and el ectronic devices. ${ }^{9,10}$ There are practical constraints associated with current technologies; lithographic methods cannot at present be used with a resolution much less than ca. $200 \mathrm{~nm}$. Most semiconducting materials, such as the II/NI or IIINI compound semiconductors, show quantum confinement behavior in the 1-20 nm size range, a smaller size than can be achieved using present lithographic methods. Herein we describe and discuss the current use of chemical methods to prepare semiconductor nanoparticle material.

\footnotetext{
* To whom correspondence should be addressed

† E-mail address: paul.obrien@man.ac.uk.
}

The preparation of nanoparticles dates back to the 19th century, with Faraday reporting the preparation of colloids of relatively monodispersed gold nanoparticles. However, until recently most research has been concerned with relatively large particles $(>100 \mathrm{~nm})$ outside the size range at which interesting effects, on the intrinsic properties of semiconductor nanoparticles, are observed. Although some earlier examples appear in the literature, ${ }^{11}$ Matijevic, among others, devel oped reproducible synthetic methods for a wide range of near monodispersed colloidal particles. ${ }^{12,13}$ In the past decade significant progress in the synthesis of semiconductor nanoparticle materials showing quantum size effects has been achieved.

\section{Theoretical Considerations}

Typically for the 1-20 nm size range semiconductor nanocrystallites show optical, electronic, and mechanical properties distinct from those of the corresponding bulk material.

Bulk Semiconductors. Macrocrystalline semiconductors, free of defects, consist of three-dimensional 
Table 1. Properties and Applications of Group IV and Compound Semiconductors (Adapted from Ref 14)

\begin{tabular}{|c|c|c|c|c|c|c|c|}
\hline \multirow[b]{2}{*}{ compd } & \multirow[b]{2}{*}{ band gapa/eV } & \multirow[b]{2}{*}{ type $^{b}$} & \multicolumn{2}{|c|}{ effective masses } & \multirow[b]{2}{*}{ structure } & \multirow[b]{2}{*}{ lattice spacing $/ \AA$} & \multirow[b]{2}{*}{ applications } \\
\hline & & & $m_{e}^{*}$ & $m_{h}^{*}$ & & & \\
\hline $\mathrm{Si}$ & 1.11 & $\mathrm{i}$ & $\begin{array}{l}0.98\left(m_{l}\right) \\
0.19\left(m_{t}\right)\end{array}$ & 0.52 & $\begin{array}{l}\text { IV Materials } \\
\text { diamond }\end{array}$ & 5.43 & $\begin{array}{l}\text { integrated circuits, } \\
\text { power electronics }\end{array}$ \\
\hline $\mathrm{Ge}$ & 0.67 & $\mathrm{i}$ & $\begin{array}{l}1.58\left(\mathrm{~m}_{\mathrm{l}}\right) \\
0.08\left(\mathrm{~m}_{\mathrm{t}}\right)\end{array}$ & 0.3 & diamond & 5.66 & \\
\hline $\begin{array}{l}\text { GaP } \\
\text { GaAs } \\
\text { GaSb } \\
\text { InP } \\
\text { InAs } \\
\text { InSb }\end{array}$ & $\begin{array}{l}2.25 \\
1.43 \\
0.69 \\
1.28 \\
0.36 \\
0.17\end{array}$ & $\begin{array}{l}i \\
d \\
d \\
d \\
d \\
d\end{array}$ & $\begin{array}{l}0.13 \\
0.07 \\
0.045 \\
0.07 \\
0.028 \\
0.0133\end{array}$ & $\begin{array}{l}0.67 \\
0.5 \\
0.39 \\
0.40 \\
0.33 \\
0.18\end{array}$ & $\begin{array}{l}\text { IIIN Materials } \\
\text { zinc blend } \\
\text { zinc blend } \\
\text { zinc blend } \\
\text { zinc blend }\end{array}$ & $\begin{array}{l}5.450 \\
5.653 \\
6.095 \\
5.8687 \\
6.058 \\
6.4787\end{array}$ & $\begin{array}{l}\text { LED } \\
\text { high-speed integrated circuits, displays } \\
\text { thermal imaging devices } \\
\text { transistor devices }\end{array}$ \\
\hline $\mathrm{CdS}$ & 2.53 & $d$ & 0.20 & $\begin{array}{l}5 / / \\
0.7 \perp\end{array}$ & $\begin{array}{l}\text { IINI Materials } \\
\text { wurtzite }\end{array}$ & $\begin{array}{l}\text { a: } 4.136 \\
\text { c: } 6.713\end{array}$ & photovoltaic cells \\
\hline CdSe & 1.74 & $d$ & 0.13 & $\begin{array}{l}2.5 / / \\
0.4 \perp\end{array}$ & wurtzite & $\begin{array}{l}\text { a: } 4.299 \\
\text { c: } 7.010\end{array}$ & photovoltaic cells \\
\hline CdTe & 1.50 & $d$ & 0.11 & 0.35 & zinc blende & 6.477 & $\begin{array}{l}\text { photovoltaic cells, } \\
\text { electrooptic modulators }\end{array}$ \\
\hline ZnS & 3.8 & $d$ & 0.28 & $\begin{array}{l}>1 / / \\
0.5 \perp\end{array}$ & wurtzite & $\begin{array}{l}\text { a: } 3.814 \\
\text { c: } 6.257\end{array}$ & phosphors, infrared windows \\
\hline ZnS & 3.6 & d & 0.39 & & zinc blend & 5.406 & \\
\hline ZnSe & 2.58 & d & 0.17 & & zinc blend & 5.667 & infrared windows, LED \\
\hline ZnTe & 2.28 & $d$ & 0.15 & & zinc blend & 6.101 & \\
\hline $\begin{array}{l}\mathrm{PbS} \\
\mathrm{PbSe}\end{array}$ & $\begin{array}{l}0.37 \\
0.26\end{array}$ & $\begin{array}{l}d \\
d\end{array}$ & $\begin{array}{l}0.1 \\
0.07\left(m_{l}\right) \\
0.039\left(m_{t}\right)\end{array}$ & $\begin{array}{l}0.1 \\
0.06\left(\mathrm{~m}_{\mathrm{l}}\right) \\
0.03\left(\mathrm{~m}_{\mathrm{t}}\right)\end{array}$ & $\begin{array}{l}\text { IVNI Materials } \\
\text { sodium chloride } \\
\text { sodium chloride }\end{array}$ & $\begin{array}{l}5.936 \\
6.124\end{array}$ & $\begin{array}{l}\text { infrared sensors } \\
\text { infrared sensors }\end{array}$ \\
\hline PbTe & 0.29 & $d$ & $\begin{array}{l}0.24\left(m_{l}\right) \\
0.02\left(m_{t}\right)\end{array}$ & $\begin{array}{l}0.3\left(m_{\mathrm{l}}\right) \\
0.02\left(\mathrm{~m}_{\mathrm{t}}\right)\end{array}$ & sodium chloride & 6.460 & infrared sensors \\
\hline
\end{tabular}

networks of ordered atoms. The translational periodicity of the crystal imposes a special form on the electronic wave functions. An electron in the periodic potential field of a crystal can be described using a Bloch type wave function (eq 1 ), where $u(r)$ represents a Bloch function modulating the plane wave $\phi(\mathrm{kr})$ of wave vector $\mathbf{k}$.

$$
\begin{gathered}
\psi(\mathrm{r})=\phi(\mathrm{kr}) \mathrm{u}(\mathrm{r}) \\
\mathrm{u}(\mathrm{r}+\mathrm{n})=\mathrm{u}(\mathrm{r}) \quad \mathrm{n} \text { integer }
\end{gathered}
$$

In a bulk semiconductor the large number of atoms leads to the generation of sets of molecular orbitals with very similar energies which effectively form a continuum. At $0 \mathrm{~K}$ the lower energy levels, or valence band, are filled with electrons, while the conduction band consisting of the higher energy levels is unoccupied. These two bands are separated by an energy gap $\left(E_{g}\right)$, the magnitude of which is a characteristic property of the bulk macrocrystalline material (at a specific temperature). Materials normally considered as semiconductors typically exhibit band gaps in the range 0.3$3.8 \mathrm{eV}$ (Table 1).

At temperatures above $0 \mathrm{~K}$, el ectrons in the valence band may receive enough thermal energy to be excited across the band gap into the conduction band. An excited electron in the conduction band together with the resulting hole in the valence band forms an "electron-hole pair". The conductivity $(\sigma)$ of the semiconductor is governed by the number of electron-hole pairs, the charge carrier concentration (n, normally expressed in terms of the number of particles per cubic centimeter), and their mobility $(\mu)$. Thus conductivity can be expressed as the sum of the electrical conductivities of electrons and holes, eq 3 ( $q$ is the charge of the carrier). In conventional semiconductors electrons and holes are the charge carriers. They exist in small numbers as compared to conductors. However, the carrier mobilities in semi conductors are substantially larger than in many conductors.

$$
\sigma=\mathrm{qn}_{\mathrm{e}} u_{\mathrm{e}}+\mathrm{qn}_{\mathrm{h}} \mu_{\mathrm{h}}
$$

The charge carriers in a semiconductor can form a bound state when they approach each other in space. This bound electron-hole pair, known as a Wannier exciton, is delocalized within the crystal lattice and experiences a screened Coulombic interaction. The Bohr radius of the bulk exciton is given by eq 4 ( $\epsilon$ represents the bulk optical dielectric coefficient, e the el ementary charge, and $m_{e}^{*}$ and $m_{h}{ }^{*}$ the effective mass of the electron and hole, respectively).

$$
a_{B}=\frac{\hbar^{2} \epsilon}{e^{2}}\left[\frac{1}{m_{e}^{*}}+\frac{1}{m_{h} *}\right]
$$

Nanocrystalline Semiconductors. Two fundamental factors, both related to the size of the individual nanocrystal, distinguish their behavior from the corresponding macrocrystalline material. The first is the high dispersity (large surface/volume ratio) associated with the particles, with both the physical and chemical properties of the semi conductor being particularly sensitive to the surface structure. The second factor is the actual size of the particle, which can determine the electronic and physical properties of the material. The absorption and scattering of incident light in larger 
colloidal particles is described by Mie's theory. However the optical spectra of nanocrystalline compound semiconductors ${ }^{1-8}$ which show blue shifts in their absorption edge as the size of the particle decreases cannot be explained by classical theory. ${ }^{15-18}$ Such size dependent optical properties are examples of the size quantization effect which occurs ${ }^{15}$ when the size of the nanoparticle is smaller than the bulk-exciton Bohr radius, $\mathrm{a}_{\mathrm{B}}$ (eq 4), of the semi conductor. Equation 5 defines, for a spherical crystallite of radius $\mathrm{R}$, the region of intermediate character between that of a "molecule" and that of the bulk material (I is the lattice spacing)

$$
\mathrm{I} \ll \mathrm{R} \leq \mathrm{a}_{\mathrm{B}}
$$

Charge carriers in semiconductor nanocrystallites are confined within three dimensions by the crystallite. In the case of ideal quantum confinement the wave function in eq 1 has to satisfy the boundary conditions of

$$
\psi(r \geq \mathrm{R})=0
$$

For nanoparticles the electron and hole are closer together than in the macrocrystalline material, and as such the Coulombic interaction between electron and hole cannot be neglected; they have higher kinetic energy than in the macrocrystalline material. On the basis of the effective mass approximation, Brus showed ${ }^{2,16,17}$ for $\mathrm{CdE}(\mathrm{E}=\mathrm{S}$ or $\mathrm{Se}$ ) nanocrystallites that the size dependence on the energy of the first el ectronic transition of the exciton (or the band gap shift with respect to the typical bulk value) can be approximately calculated using

$$
\Delta \mathrm{E} \cong \frac{\hbar^{2} \pi^{2}}{2 \mathrm{R}^{2}}\left[\frac{1}{\mathrm{~m}_{\mathrm{e}}^{*}}+\frac{1}{\mathrm{~m}_{\mathrm{h}}{ }^{*}}\right]-\frac{1.8 \mathrm{e}^{2}}{\epsilon \mathrm{R}}
$$

Equation 7 is an analytical approximation for the first electronic transition of an exciton, which can be described by a hydrogenic Hamiltonian,

$$
\hat{\mathrm{H}}=\frac{-\hbar^{2}}{2 \mathrm{~m}_{\mathrm{e}}^{*}} \nabla_{\mathrm{e}}^{2}-\frac{\hbar^{2}}{2 \mathrm{~m}_{\mathrm{h}}{ }^{*}} \nabla_{\mathrm{h}}{ }^{2}-\frac{\mathrm{e}^{2}}{\epsilon\left|\mathrm{r}_{\mathrm{e}}-\mathrm{r}_{\mathrm{h}}\right|}
$$

In eq 7 the Coulomb term shifts the first excited electronic state to lower energy, $\mathbf{R}^{-1}$, while the quantum localization terms shift the state to higher energy, $\mathrm{R}^{-2}$. Consequently, the first excitonic transition (or band gap) increases in energy with decreasing particle diameter. This prediction has been confirmed experimentally for a wide range of semiconductor nanocrystal lites, ${ }^{1-8}$ with a blue shift in the onset of the absorption of light being observed with decreasing particle diameter. Moreover, the valence and conduction bands in nanocrystalline materials consist of discrete sets of electronic levels and can be viewed as a state of matter between that of molecular and the bulk material.

Equation 7 does not account for a number of other important effects observed in real nanocrystallites, ${ }^{18}$ such as the coupling of electronic states and effects attributable to surface structure. The constants used in the model (the effective masses and the dielectric constants) are those for macrocrystalline solids. The model is not quantitatively accurate with calculations deviating from experimental values, especially for very smaller nanocrystallites. In such particles the first electronic transition is located in a region of the energy band in which the normal effective mass approximation is not valid. Although eq 7 is not valid for all types of semiconductors, from a practical point of view this model is particularly useful and the size-dependent energy shift for a number of nanocrystalline semiconductors can be estimated. Furthermore, the model also provides a useful qualitative understanding of the quantum confinement effects observed in semiconductor nanocrystallites.

Other theoretical methods have been used to explain the size-dependent electronic properties of nanoparticle semi conductors. ${ }^{19-24}$ Descriptions of the different theoretical methods can be found in the published work of Brus, ${ }^{16-18}$ Weller et al., ${ }^{19,20}$ Nosaka, ${ }^{21}$ and Wang and Herron, 22 among others. These models provide reasonable estimates for the band gap shifts observed experimentally for nanoparticles (e.g. II/VI semiconductors), provided that the particles are not too small (typically $>4 \mathrm{~nm}$ ). The empirical pseudopotential method, described by Krishna and Friesner, ${ }^{24}$ correlate well with experimental values over a wide range of particle sizes. Some properties which are not explained by the effective mass model, such as the dependence of optical properties of CdS nanoparticles on the crystal structure, can be understood by the Krishna-F riesner model ${ }^{24} \mathrm{~A}$ large number of studies have dealt with quantum size effects on the lowest excitonic transition. An understanding of the higher energy transitions has been addressed more recently. ${ }^{25}$

Optical Properties. Quantum size effects have been observed experimentally for many nanocrystalline semiconductors. ${ }^{1-8}$ The optical absorption spectrum of a nanocrystalline semiconductor provides an accessible and straightforward method for the evaluation of quantum size effects. The absorption of a photon, leading to excitation of an electron from the valence band to the conduction band, is associated with the band gap energy $\left(E_{g}\right)$. The absorption of photons with energy similar to that of the band gap, $\mathrm{h} v \geq \mathrm{E}_{\mathrm{g}}$, leads to an optical transition producing an electron in the conduction band of the semiconductor along with a hole in the valence band. Absorption of photons with energy much greater than $\mathrm{E}_{\mathrm{g}}$ leads to excitations above the conduction band edge; these electrons can lose the excess energy by radiation-less processes.

The absorption (A) of light by a semiconductor material with thickness I can be expressed by an expression analogous to the Beer law (eq 9), where $\alpha$ represents the absorption coefficient of the solid and is a function of the radiation frequency.

$$
A=\alpha \mid
$$

All electronic transitions are subject to selection rules; for semi conductors the requirements (besides $\mathrm{h} v \geq \mathrm{E}_{\mathrm{g}}$ ) is that the wave vector, $\mathbf{k}$, should be conserved. $\mathbf{k}_{\text {photon }}$ is small when compared with the wave vectors of the electron before $\left(\mathbf{k}_{\mathrm{e}}\right)$ and after excitation $\left(\mathbf{k}_{\mathrm{e}}^{\prime}\right)$.

$$
\begin{gathered}
\mathbf{k}_{\mathrm{e}}+\mathbf{k}_{\text {photon }}=\mathbf{k}_{\mathrm{e}}^{\prime} \\
\mathbf{k}_{\mathrm{e}}=\mathbf{k}_{\mathrm{e}}^{\prime}
\end{gathered}
$$




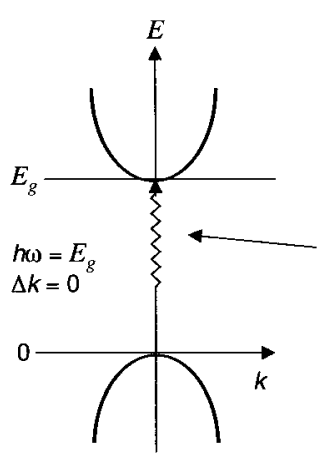

Direct transition

(a)

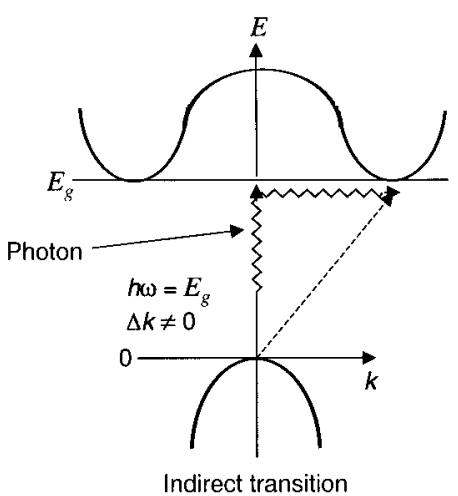

(b)
Figure 1. Excitation across the band gap by photon absorption: (a) direct process; (b) indirect process. (Adapted from $\mathrm{H}$. M. Rosenberg, The solid state; Oxford University Press: Oxford, U.K.).

The absorption coefficient for a photon of a given energy is proportional to the probability $\left(\mathrm{P}_{\mathrm{if}}\right)$, the density of states in the initial state $\left(n_{i}\right)$, and the density of available final states $\left(n_{f}\right)$. This process must be summed for all possible transitions between states separated by an energy difference equal to the energy of the incident photon

$$
\alpha(\mathrm{h} v) \propto \sum \mathrm{P}_{\mathrm{if}} \mathrm{n}_{\mathrm{i}} \mathrm{n}_{\mathrm{f}}
$$

Semiconductors in which there is conservation of the wave vector for optical transitions are referred to as direct band gap semiconductors (Figure 1 ) and have large absorption coefficients. A useful expression relating the absorption coefficient and the photon energy of a direct transition near the threshold is ${ }^{14}$ given by eq 13. Semiconductors where the lowest el ectronic transition, between the valence band and the conduction band, is formally forbidden are said to have an indirect band gap (Figure 1) and normally have small absorption coefficients.

$$
\alpha(\mathrm{h} v) \propto\left(\mathrm{E}_{\mathrm{g}}-\mathrm{h} v\right)^{1 / 2}
$$

The "band gap" energy of a nanocrystall ine semiconductor can be experimentally estimated from its optical spectrum and by using eq 13. Experimentally quantum size effects are observed as a shift toward higher energy values for the band edge (a blue shift), as compared to the typical value for the corresponding macrocrytalline material. Nanocrystall ine samples often show a peak(s) in the optical spectra at room temperature. The oscillator strength (directly proportional to the absorption coefficient) increases as particle size decreases, due to strong overlapping of the wave functions of confined charge carriers. ${ }^{1-8}$ Such effects were clearly demonstrated in a study of CdS nanocrystallites with different and well-defined size distributions. ${ }^{26}$ Decreasing the size of the CdS particles leads not only to a shift in the excitonic peak to higher energy but also to an increase in the molar absorption coefficient (Figure 2).

The absorption of electromagnetic radiation by nanocrystallite material is relatively straightforward; to understand, however, theluminescent behavior of such particles is more complicated, and the ideas that have emerged for explaining these phenomena illustrate an

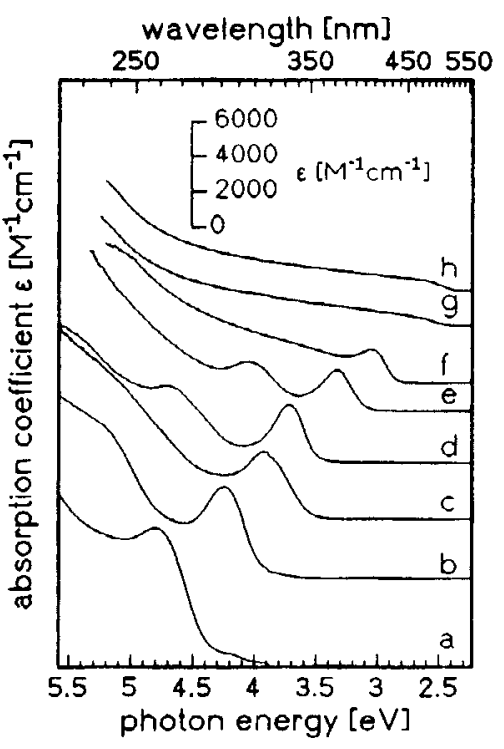

Figure 2. Electronic spectra of samples consisting of CdS nanocrystals with different mean diameters $(\AA)$ : (a) 6.4, (b) 7.2, (c) 8.0, (d) 9.3, (e) 11.6, (f) 19.4, (g) 28, and (h) 48. The excitonic transition shifts to higher energy values along with an increase in the molar absorption coefficient, as the particle size decrease. ${ }^{26}$

interesting interplay between experiment and theory. In a keynote paper, Brus explained, on the basis of theoretical and experimental studies, ${ }^{27}$ the features expected in the luminescence spectra of quantum confined semiconductors and successfully anticipated the results of many subsequent experiments. However, the understanding of the photophysics of these systems is still far from complete, and further studies on highquality samples are needed. In particular studies on the photophysics of nanocrystalline samples possessing narrow size distributions have been scarce. ${ }^{27} \mathrm{~L}$ uminescence studies on nanodispersed systems have focused mainly on CdS and CdSe. ${ }^{27,28}$ Cadmium selenide is of interest since light emission can range across the visible region simply by varying the mean diameter of the nanocrystals.

To devel op an understanding of quantum dots, it is useful to develop an appreciation of the luminescence behavior of bulk CdS. Cadmium sulfide is typically sulfur deficient, with the sulfur vacancies possessing a high electron affinity, with acquired electrons making the material n-type in nature. Charge-hole pairs generated in CdS are well-separated, with the electrons being highly localized; this leads to excited states with long lifetimes, having little or no overlap between their wave functions. The el ectrons are located at different sites, spaced apart; therefore even a shallow trap at low temperature (e.g. $10^{-2} \mathrm{eV}$ ) can localize an electron. Emission is a complex process, involving the capture of long-lived charge separated species by both shallow and deep traps followed by radiation-less processes, with the final emission from a deep trap leading to a broad red emission.

In early studies on quantum dot luminescence their behavior resembled that of the bulk material. ${ }^{27}$ Brus and co-workers suggested that sulfur vacancies, located at the surface of the material, might be important in mediating low-energy emissions. There are several reasons for this, one of which is the considerable size of 


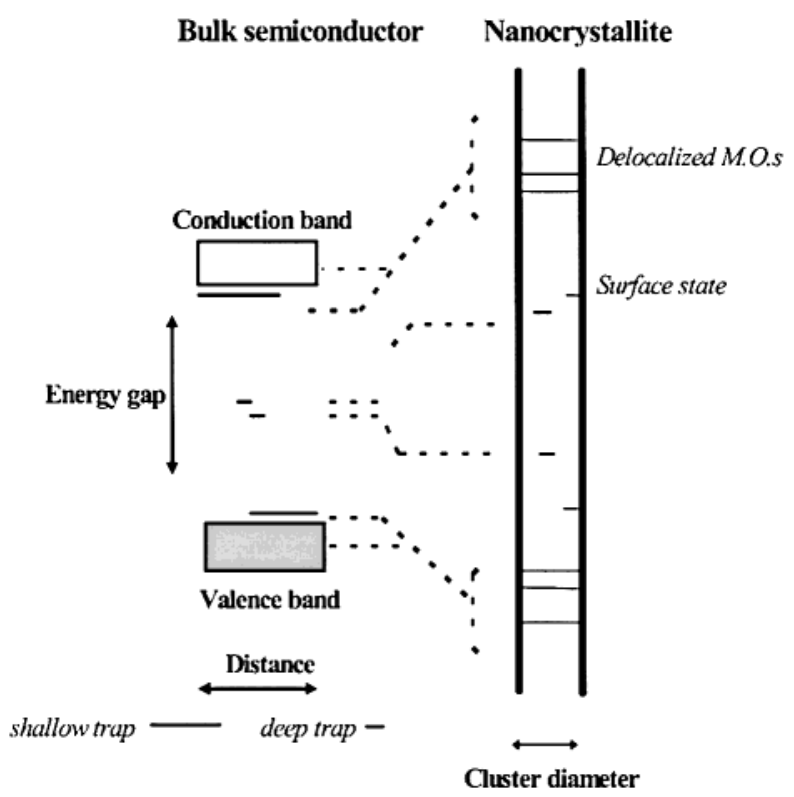

Figure 3. Spatial electronic state correlation diagram for a macrocrystalline and nanocrystalline semiconductor. ${ }^{27}$

such shallow traps. Moreover, as the size of these traps approaches that of the nanoparticle, the wave functions of the trap and excited state overlap. Transfer to these levels, in the form of a separate event, should subsequently be minimized, and the possibility of el ectronhole recombination, with emission close to the absorption peak of the bound exciton, can become the predominant event. Electronic states important in determining emission are illustrated in Figure 3. The lifetimes of the various species are also considered important in explaining the observed spectra.

These suggestions have been confirmed by a number of experiments, which show the effects on the luminescence properties of nanodispersed IINI materials to be dependent on surface derivatization. For the surface derivatization of nanoparticles, two main approaches have been outlined, the growth of a second phase on the surface of colloidally prepared material, ${ }^{29}$ sometimes referred to as an activation step, with examples including the post-treatment of CdS with hydroxy groups to form $\mathrm{Cd}(\mathrm{OH})_{2}$, or the use of ligands such as thiolates (Figure 4). ${ }^{30,31}$ Surface derivatization has the effect of minimizing surface defects and may enhance the possibility of electron-hole recombination. The second approach centers around the derivatization of nanoparticulates with solvent molecules, e.g. when preparing nanoparticles from organometallic precursors, using trin-octylphophine oxide as the solvent, 32 which may subsequently be exchanged for alternative ligands such as pyridine.

\section{Preparative Methods for the Synthesis of Nanoparticles}

Many synthetic methods for the preparation of nanodispersed material have been reported; several routes involve colloidal chemistry, with others involving the kinetically controlled precipitation of nanocrystallites, using organometallic compounds. ${ }^{1-8}$ The use of clusters, as building blocks to nanocrystallites, will be dealt with in another section.

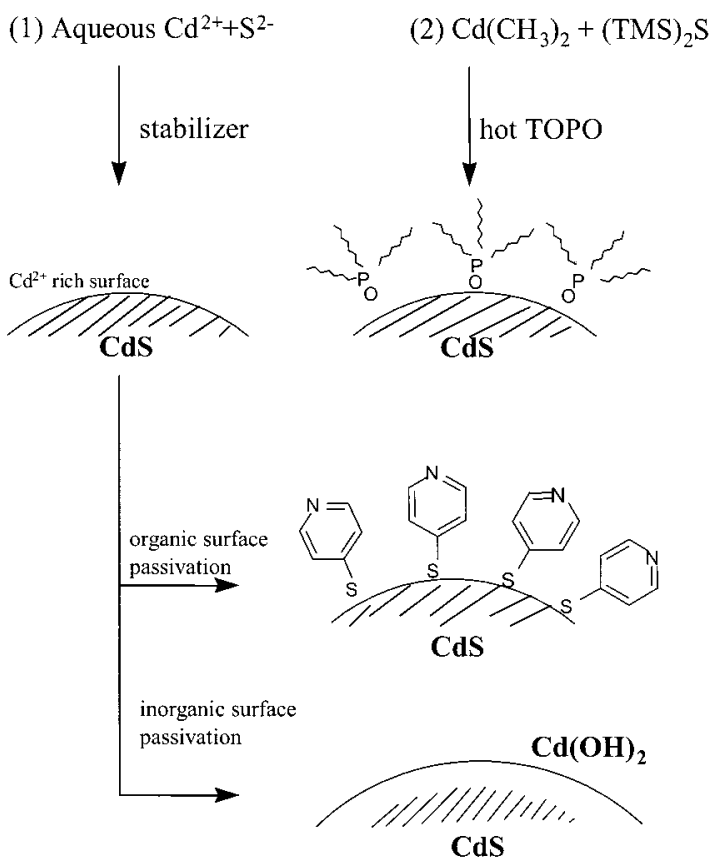

Figure 4. Two major routes for surface chemical passivation of nanocrystals.

I deally, the synthetic method employed should lead to samples of crystalline nanoparticulates of high purity, with a narrow size distribution, that are surface de rivatized. Particles satisfying such criteria may be useful in the fabrication of semiconducting devices. Herein, we focus on synthetic methods for the preparation of compound semiconductor nanocrystallites. The syntheses of elemental nanoparticle semiconductors and metals such as $\mathrm{Ag}^{1,33} \mathrm{Pd}^{134} \mathrm{Au}^{35}$ and $\mathrm{Cu}^{36}$ have been the subject of a number of other reviews, but will be briefly mentioned. The preparation and properties of nanocrystalline refractory compounds, such as carbides, borides, nitrides, and oxides, have been reviewed by Andrievski ${ }^{37}$ and will not be considered any further in this article.

Arrested Precipitation in Solution. Controlled precipitation reactions can yield dilute suspensions of quasi monodispersed particles. This synthetic method sometimes involves the use of seeds of very small particles for the subsequent growth of larger ones. 38,39 The first report correlating semiconductor particles size with optical properties was made in 1967 by Berry who studied both CdS and Agl particles. ${ }^{11}$ Recently more extensive studies have been undertaken by Brus on $\mathrm{CdS}$ and $\mathrm{ZnS},{ }^{40,41} \mathrm{Henglein}$ on silver, ${ }^{1,42}$ and Grätzel on $\mathrm{TiO}_{2}$ particles. 6,43

Brus et al. ${ }^{40}$ described a synthetic process for the preparation of CdS nanoparticles which involves the controlled nucleation of CdS on mixing of dilute aqueous solutions of $\mathrm{CdSO}_{4}$ and $\left(\mathrm{NH}_{4}\right)_{2} \mathrm{~S}$. The stability of the initially small crystallites formed is influenced by the dynamic equilibrium illustrated in

$$
(\mathrm{CdS})_{\text {crystal }} \longleftrightarrow\left(\mathrm{Cd}^{2+}\right)_{\text {solv }}+\left(\mathrm{S}^{2-}\right)_{\text {solv }}
$$

Small crystallites are less stable than larger ones and tend to dissol ve into their respective ions. Subsequently, the dissolved ions can recrystallize on larger crystallites, which are thermodynamically more stable (Ostwald 
ripening). The use of acetonitrile, as a solvent, or the addition of styrene/maleic anhydride copolymer allowed the preparation of stable CdS nanoparticles, with an average size of 34 and $43 \AA$, respectively. ${ }^{40}$ Cubic ZnS and CdS nanocrystallites were synthesized in aqueous and methanolic solutions without organic surfactant (capping agent). ${ }^{41}$

Henglein, Weller, and co-workers made significant insight into the photochemistry of CdS semiconductor nanocrystallites, $1,4,5$ using CdS colloids prepared by controlled precipitation methods. ${ }^{29,44-48}$ To obtain highly monodispersed nanoparticles, postpreparative separation techniques such as size exclusion chromatography ${ }^{46}$ and gel electrophoresis were employed. ${ }^{47} \mathrm{Gel}$ el ectrophoresis was found to be superior to other separation techniques. Similarly, Boxall and Kelsall ${ }^{49-51}$ have published work on the el ectrophoresis of $\mathrm{TiO}_{2}$ colloids.

Weller et al. synthesized nanocrystallites of $Z n_{3} P_{2}$ and $\mathrm{Cd}_{3} \mathrm{P}_{2}$ by the injection of phosphine $\left(\mathrm{PH}_{3}\right)$ into solutions containing metal salts; ${ }^{44,52}$ control of particle size was achieved by varying the phosphine concentration and the temperature of the reaction. Samples of both $\mathrm{Zn}_{3} \mathrm{P}_{2}$ and $\mathrm{Cd}_{3} \mathrm{P}_{2}$ showed remarkable quantum size effects, as observed by changes in the col or of the products. Bulk $\mathrm{Cd}_{3} \mathrm{P}_{2}$ is black, whereas a solution containing small nanocrystallites ( $15 \AA$ in diameter) of this material are colorless with an excitonic maximum in the optical spectrum at around $310 \mathrm{~nm}$. Moreover, the color of $\mathrm{Cd}_{3} \mathrm{P}_{2}$ changes from black, macrocrystalline (band gap of $0.53 \mathrm{eV}$ ) through brown (30 A particle) red, orange, and yellow to white, ( $15 \AA$ band gap ranging from 0.8 to $0.95 \mathrm{eV}$ ). Hexametaphosphate was used as a stabilizer to prevent particle aggregation. The sample fluoresced when excited at $300 \mathrm{~nm} .52$ The preparation of materials for infrared applications is currently an active area of research, with $\mathrm{Cd}_{3} \mathrm{P}_{2}, \mathrm{PbS}$, and $\mathrm{Ge}$ being potential candidates for such purposes (Table 1 ).

The preparation of elemental nanoparticles of both silicon 53,54 and germanium, 55,56 is also of interest since both have indirect band gaps in the near-infrared region (Table 1). Preci pitation methods such as those used in the synthesis of IINI semiconductors are not suitable for $\mathrm{Ge}$ or $\mathrm{Si}$ particle synthesis due to crystallization problems. Weller et al. ${ }^{55}$ described the synthesis of germanium nanocrystallites by a wet-chemical method, which involved stirring $\mathrm{GeCl}_{4}$ with lithium naphthal ide in tetrahydrofuran,

$$
\mathrm{nGeCl}{ }_{4}+4 \mathrm{nLi}\left[\mathrm{C}_{10} \mathrm{H}_{8}\right] \rightarrow \mathrm{Ge}_{\mathrm{n}}+4 \mathrm{nC}_{10} \mathrm{H}_{8}+4 \mathrm{nLiCl}
$$

Germanium tetrachloride was added to a solution containing an excess of naphthalide; this led to the formation of germanium clusters. Laser illumination of hexane solutions containing these clusters enhanced growth and improved the crystallinity of the resulting particles. Germanium nanocrystal lites ( $>200,110$, and $60 \AA$ ) have also been obtained by Alivisatos et al..$^{56}$ via an ultrasonic mediated reduction of chlorogermanes and organochlorogermanes with a sodium/potassium (NaK) alloy, in heptane. The crystallinity of the particles was improved by annealing, in a closed vessel at $270{ }^{\circ} \mathrm{C}$. Fojtik and Henglein ${ }^{57}$ described the synthesis and luminescence properties of colloidal oxide-coated silicon particles, obtained from the combustion of silane. Recently a composite silica sol-gel incorporating lumines- cent Si nanoparticles has been reported. ${ }^{58}$ The sol-gel monolith was prepared by hydrolysis of tetraethoxysilane in the presence of a range of amino acids, which confers stability to the Si nanoparticles and passivate their surfaces. ${ }^{58}$

Surface modification of semiconductor nanocrystallites can lead to el ectro- or photoluminescent systems, which may have applications in light emitting devices. One possibility for the preparation of this type of material is the growth of a solid, $A$, on the surface of a second solid, B, with the latter acting as a seed for the heterogeneous nucleation of the former. Examples of the use of this method include $\mathrm{TiO}_{2} / \mathrm{Cd}_{3} \mathrm{P}_{2},{ }^{59} \mathrm{HgS} / \mathrm{CdS}, 60$ $\mathrm{PbS} / \mathrm{CdS},{ }^{61,62} \mathrm{CdS} / \mathrm{H} \mathrm{gS},{ }^{63} \mathrm{ZnS} / \mathrm{CdSe}{ }^{64} \mathrm{ZnSe} / \mathrm{CdSe}$, ${ }^{65}$ and $\mathrm{CdSe} / \mathrm{ZnS} .{ }^{66}$ However, there are constraints in the use of this technique, in relation to both the relative solubility of the solids as well as lattice mismatch between phases $A$ and $B$. The preparation of structures termed "quantum dot quantum well systems" (A/B/A) such as $\mathrm{CdS} / \mathrm{HgS} / \mathrm{CdS}, 67,68$ has also been reported such as in the case of $\mathrm{CdS} / \mathrm{HgS} / \mathrm{CdS}$ consisting of a CdS core, a $\mathrm{HgS}$ quantum well of $1-3$ monolayers, capped by $1-5$ monolayers of CdS. The synthesis (eq 16) involves the growth of HgS on CdS ( $52 \AA$ diameter) by ion replacement, which is achieved by adding aqueous solutions of $\mathrm{Hg}\left(\mathrm{ClO}_{4}\right)_{2}$ to solutions of $\mathrm{CdS}$ particles. Substitution of $\mathrm{Cd}^{2+}$ for $\mathrm{Hg}^{2+}$ ions is thermodynamically favored, since the solubility products of CdS and HgS are $5 \times$ $10^{-28}$ and $1.6 \times 10^{-52}$, respectively. Also, there is a good match between the lattice constants for cubic CdS (5.818 $\AA)$ and cubic HgS (5.851 $\AA$ ), eq 16 . Finally the reprecipitation of displaced $\mathrm{Cd}^{2+}$ ions, on the surface of CdS/ $\mathrm{HgS}$ particles, is achieved by the dropwise addition of a dilute solution containing $\mathrm{H}_{2} \mathrm{~S}$, with the final particle diameter being estimated at $77 \pm 12 \AA$. The authors reported fluorescence measurements in which the band edge emission for $\mathrm{CdS} / \mathrm{HgS} / \mathrm{CdS}$ is shifted to lower energy values with increasing thickness of the $\mathrm{HgS}$ layer. ${ }^{68}$

$$
(\mathrm{CdS})_{\mathrm{m}}+\mathrm{nHg}^{2+} \rightarrow(\mathrm{CdS})_{\mathrm{m}-\mathrm{n}}(\mathrm{HgS})_{\mathrm{n}}+\mathrm{nCd}^{2+}
$$

Other examples of the preparation of semiconductor nanocrystallites by solution methods can be found in the literature. ${ }^{1-8}$ Solution methods provide a cheap route to many nanoparticle materials. However, the low temperatures typically used in those methods mean that any defects formed in the early stages of the preparation are likely to be trapped and the crystallinity of the material will be low. Also several important semiconductors are not easily obtained using this preparative method, with some being air and/or moisture sensitive, e.g. GaAs and InSb.

Synthesis in a Structured Medium. A number of matrices have been used for the preparation of semiconductor nanoparticles including: zeolites, ${ }^{69}$ layered solids, ${ }^{70}$ molecular sieves, ${ }^{71-73}$ micelles/microemulsions, ${ }^{74-78}$ gels, ${ }^{79-81}$ polymers, ${ }^{82-86}$ and glasses. ${ }^{87}$ These matrices can be viewed as nanochambers which limit the size to which crystallites can grow. The properties of the nanocrystallites are determined, not only by the confinements of the host material but also by the properties of the system, which include the internal/ external surface properties of the zeolite and the lability of micelles. As a consequence of the confinements of the 


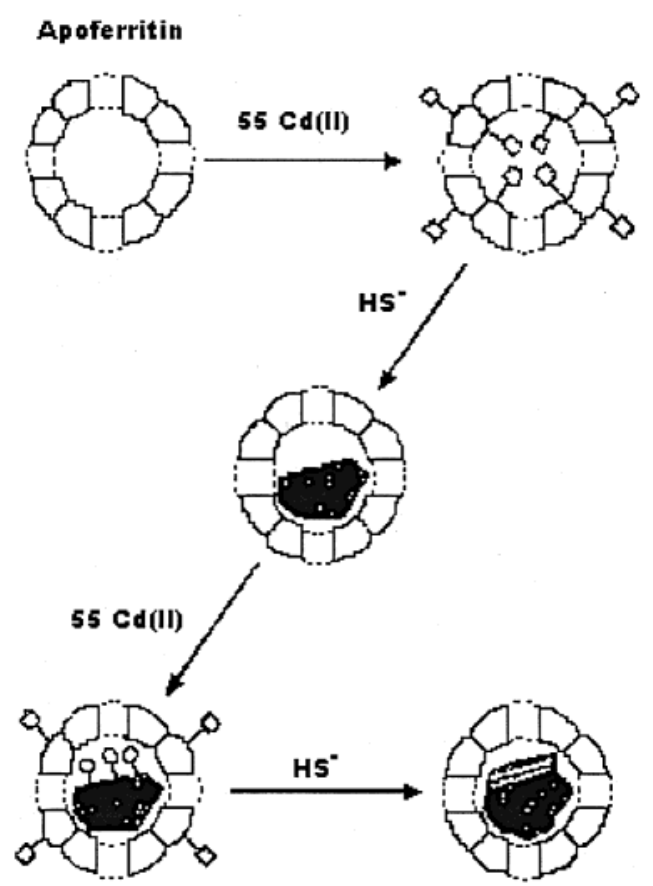

CdS-Ferritin

Figure 5. Reaction scheme for the synthesis of CdS-ferritin nanocomposites. ${ }^{91}$

medium used, the range of particle sizes possible is limited; e.g. in zeolites the nanocrystallites diameter is limited by the pore size of the zeolite (typically smaller than $20 \AA$ ).

Wang and Herron 69 have studied the optical properties of both CdS and PbS clusters encapsulated in zeolites. The nanocrystallites were prepared in two different zeolites; modernite (unidirectional channels of $7 \AA$ diameter) and zeolite $Y$ (13 \& diameter channels with cages of tetrahedral symmetry interconnected by $8 \AA$ windows and $5 \AA$ cages interconnected by $3 \AA$ windows). For the preparation of CdS in zeolite $Y$, the sodium cations in the zeolite were first ion-exchanged with cadmium cations, by treatment with aqueous $\mathrm{Cd}$ $\left(\mathrm{NO}_{3}\right)_{2}$ at $\mathrm{pH} 5$. This was followed by passing hydrogen sulfide $\left(\mathrm{H}_{2} \mathrm{~S}\right)$ gas over the sample. ${ }^{69}$ Depending on the loading level of cadmium ions within the zeolite, different sizes of CdS clusters could be obtained. At low loading levels (1:1 metal/sulfide) CdS clusters with an average size less than $13 \AA$ were obtained. These gave an absorption peak at around $280 \mathrm{~nm}$ in their optical spectra. When an excess of cadmium was used, the individual clusters aggregated into an extended structure, modulated by the internal cavities of the zeolite. These produced optical spectra showing an excitonic shoulder near $350 \mathrm{~nm}$ corresponding to CdS clusters of approximately $28 \AA$ in diameter. The small dimensions reported in this work ${ }^{69}$ are typical of nanoparticles obtained when zeolites are used as the host structure.

Stable, cubic-phase, PbS nanoparticles were prepared in a polymeric matrix by exchanging $\mathrm{Pb}^{2+}$ ions in an ethylene-15\% methacrilic acid copolymer followed by reaction with $\mathrm{H}_{2} \mathrm{~S} .82$ The size of the PbS nanoparticles was dependent on the initial concentration of $\mathrm{Pb}^{2+}$ ions and have diameters ranging from 13 to $125 \AA$. The smallest particles (13 $\AA$ ) are reported to be molecular in nature and exhibit discrete absorption bands in their optical spectra. Two theoretical models, which take into account the effect of nonparabolicity, were proposed in order to explain the observed size-dependent optical shifts for PbS nanocrystallites. ${ }^{82}$ The authors reported that the effective mass approximation fails for $\mathrm{PbS}$ nanocrystallites. However, Nosaka ${ }^{21}$ showed that calculations using an effective mass approximation model could be improved on for PbS nanocrystals. Lead chalcogenides are unusual semiconductors in that their optical band gaps decrease as the temperature de creases. Due to their large bulk exciton radius, strong quantum size effects have been observed for particles larger than $10 \mathrm{~nm}$ in diameter. ${ }^{82}$

Steigerwald et al. prepared capped CdSe, ZnS, ZnS/ $\mathrm{CdSe}$, and $\mathrm{CdSe} / \mathrm{ZnS}$ nanocrystallites from inverse micelar solutions. ${ }^{64,88}$ Silylchalcogenide reagents were added to microemulsions containing the appropriate metal ions. The particle surfaces were subsequently capped; for example with phenyl groups or with other semiconductor materials such as ZnS.

$$
\begin{gathered}
\mathrm{CdCl}_{2}+\mathrm{Se}\left(\mathrm{SiMe}_{3}\right)_{2} \underset{-2 \mathrm{Me}_{3} \mathrm{SiCl}}{ } \mathrm{CdSe} \\
\mathrm{ZnEt}_{2}+\mathrm{Se}\left(\mathrm{SiMe}_{3}\right)_{2} \underset{-2 \mathrm{SiEtMe}_{3}}{\longrightarrow} \mathrm{ZnSe} \\
\mathrm{CdMe}_{2}+\mathrm{Te}\left(\mathrm{Si}^{\mathrm{i}} \mathrm{PrMe}_{2}\right)_{2} \underset{-2 \mathrm{SiPrMe}_{3}}{\longrightarrow} \mathrm{CdTe}
\end{gathered}
$$

Silylorganochalcogenides react readily with metal salts or simple metal alkyls to form metal-chal cogenide bonds as in eqs 17-19.89 Micelle stabilized CdSe nanocrystallites, with $\mathrm{Cd}^{2+}$ rich surfaces, react similarly with $\mathrm{R}\left[\left(\mathrm{CH}_{3}\right)_{3} \mathrm{Si}\right]_{2} \mathrm{Se}$ to give larger CdSe crystallites encapsulated by a layer of organic ligands (R). These surface passivated crystallites can be isolated as powders, which are soluble in organic solvents such as pyridine. ${ }^{77} \mathrm{Se}$ NMR spectra of three size distributions of organiccapped CdSe particles were reported, with each giving different spectra, ${ }^{90}$ consisting of broad lines corresponding to bulk material along with additional peaks appearing at higher field and becoming more intense with decreasing particle size.

Several types of nanoparticles prepared from synthesis involving biological related processes, biomimetic, have been reported. ${ }^{91-93}$ For example, using empty polypeptide cages found in the iron storage protein ferritin; bio-inorganic nanocomposites of CdS-ferritin can be synthesized (Figure 5). ${ }^{91}$ Another approach to nanocrystallite synthesis in a matrix was devel oped by Choi and Shea, ${ }^{79,80}$ who report using porous inorganicorganic xerogel (polysilsesquioxanes) to produce CdS (60 and $90 \AA)^{79}$ and chromium particles (10-100 $\AA$ ). ${ }^{80}$ The chromium precursor used was a zerovalent arene tricarbonyl chromium complex, introduced as a component of the xerogel matrix, which after heating under vacuum produced chromium nanoparticles. By first doping CdS into the starting material, two different phases of chromium and CdS are reported to be obtained. ${ }^{80}$

Molecular Precursor Methods. A powerful method for the preparation of semiconductor nanocrystallites has been described by Murray, Norris, and Bawendi; 32 solutions of $\left(\mathrm{CH}_{3}\right)_{2} \mathrm{Cd}$ and tri-n-octylphosphine selenide (TOPSe) are injected into hot tri-n-octylphosphine oxide (TOPO) in the temperature range $120-300{ }^{\circ} \mathrm{C}$. This produced TOPO capped nanocrystallites of CdSe. ${ }^{32}$ The 


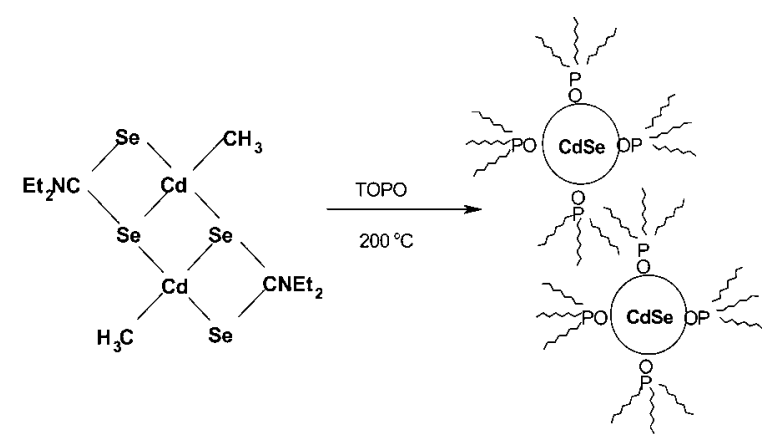

Figure 6. Single-source approach for preparing semiconductor nanocrystallites in TOPO.

size distribution of the particles is controlled mainly by the temperature at which the synthesis is undertaken, with larger particles being obtained at higher temperatures. The combination of tri-n-octylphosphine/tri-noctylphosphine oxide (TOP/TOPO) allowed for slow steady growth conditions above $280{ }^{\circ} \mathrm{C}$. The TOPO method has advantages over other synthetic methods, including, near monodispersity ( $\sigma \cong 5 \%$ ) and scale grams of material can be produced. The surface nature of CdSe/TOPO nanocrystallites has been studied by nuclear magnetic resonance spectroscopy ${ }^{94}$ and X-ray photoelectron spectroscopy. ${ }^{95} \mathrm{~F}$ or these methods surface coverage, the percentage of surface sites bound to TOPO molecules, through a metal-oxygen dative bond, increases from $30 \%(d \approx 60 \AA)$ to $60 \%(d \approx 18 \AA)$ as the particle size decreases. Variations in surface coverage with particle size can be explained ${ }^{95}$ by steric effects; interactions between surface bound bulky neighboring capping molecules (TOPO) predominates in larger particles; moreover, smaller particles can accommodate higher percentage levels of surface coverage, due to less steric hindrance. More detailed studies on the surface nature of passivated nanocrystalline are needed; in fact, it has been reported that the surfaces of nanocrystallites are faceted with preferred crystallographic directions of growth producing nonspherical particles, which in turn leads to the formation of particles with distinct physical properties. ${ }^{8,96}$

One of the limitations of the TOPO method is the use of hazardous compounds such as dimethylcadmium, $\left(\mathrm{CH}_{3}\right)_{2} \mathrm{Cd}$-especially at high temperatures. An approach for overcoming this problem involves the use of single molecule precursors, a single compound containing all elements required within the nanocrystallite, such as al kyldisel eno- or alkyldithiocarbamato complexes, Figure 6. ${ }^{97,98}$ The fabrication of semiconductor nanocrystallites from single molecule precursors is a one step process, typically carried out at temperatures in the range $200-250^{\circ} \mathrm{C}$. A similar approach in which nonair-sensitive lead(II) alkyldithio- or alkyldiselenocarbamates were thermally decomposed, under controlled conditions, led to the synthesis of cubic phase $\mathrm{PbS}^{99}$ and $\mathrm{PbSe}^{100}$ nanocrystallites, respectively.

The use of single source precursors in the deposition of thin film compound semiconductors by MOCVD techniques has been extensively studied.101-104 However, related compounds can be used to prepare compound semiconductor nanoparticles, such as oligomeric $\mathrm{Cd}\left(\mathrm{Se}\left(\mathrm{C}_{2} \mathrm{H}_{5}\right)\right)_{2}{ }^{105}$ or metal dithiocarbamates ${ }^{106}$ in 4-ethylpyridine. Another approach, which has been success- fully investigated in our laboratories, is to replace $\left(\mathrm{CH}_{3}\right)_{2} \mathrm{Cd}$ with a more stable compound such as the amine adduct, $\mathrm{Cd}\left(\mathrm{CH}_{3}\right)_{2} \cdot \mathrm{N}\left(\mathrm{C}_{2} \mathrm{H}_{5}\right)_{3} \cdot{ }^{107}$

$$
\begin{gathered}
\mathrm{InCl}_{3}+\text { TOPO } \stackrel{100^{\circ} \mathrm{C}, 12 \mathrm{~h}}{\longrightarrow} \mathrm{In}-\mathrm{TOPO} \stackrel{\mathrm{P}\left(\mathrm{Si}_{\left.\left(\mathrm{CH}_{3}\right)_{3}\right)_{3}, 265^{\circ} \mathrm{C} \text {, days }}^{\longrightarrow}\right.}{\mathrm{InP} / \mathrm{TOPO}} \\
\operatorname{InP} / \mathrm{TOPO} \stackrel{\text { surfactant(S),100 }{ }^{\circ} \mathrm{C} \text {, days }}{\longrightarrow} \mathrm{InP} /(\mathrm{TOPO}+\mathrm{S}) \quad(20)
\end{gathered}
$$

The conventional TOPO method was recently used 108 by Alivisatos et al. in the synthesis of capped InP nanocrystals (20-50 $\AA$ in diameter). The reaction involved dissolving $\mathrm{InCl}_{3}$ in hot TOPO followed by addition of $\mathrm{P}\left(\mathrm{Si}\left(\mathrm{CH}_{3}\right)_{3}\right)_{3}$, with annealing of the resulting InP nanocrystals, eq 20. The band gap for bulk InP is $1.28 \mathrm{eV}$, whereas the InP nanocrystallites produced exhibit values ranging from 1.7 to $2.4 \mathrm{eV} .108$ The percentage coverage of the I $\mathrm{nP}$ particles with TOPO was found ${ }^{108}$ to range from 30 to $70 \%$, depending on the size of the particles. Values for the band edge and deep trap emissions were reported to shift with the mean size of the nanocrystallites, with stronger emissions observed for smaller InP particles and when oxidation of the surface had occurred. F or InAs, prepared by a similar TOPO method, using the dehalosilylation reaction between $\mathrm{As}\left[\mathrm{Si}\left(\mathrm{CH}_{3}\right)_{3}\right]_{3}$ and $\mathrm{InCl} \mathrm{n}_{3}$, surface oxi dation did not change the properties of the resulting particles. ${ }^{109}$

IIIN semiconductors exhibit less ionic character than their IINI analogues and thus do not crystallize as readily. Kaner et al. ${ }^{110}$ used solid-state metathesis involving the reaction of sodium pnictides with group III halides, at high temperature, in a closed vessel, to produce III/N nanoparticles. A relatively low-temperature method involving similar reactions in organic solvents has been reported for the preparation of GaP and GaAs nanoparticles, using gallium (III) halides and $(\mathrm{Na} / \mathrm{K})_{3} \mathrm{E}(\mathrm{E}=\mathrm{P}, \mathrm{As}){ }^{111}$ This method avoids the use of hazardous phosphines or arsines. Nanocrystallites of I $\mathrm{nAs}$ and I $\mathrm{nP}$ were also synthesized ${ }^{112}$ from the reaction of $\mathrm{InX}_{3}(\mathrm{X}=\mathrm{Cl}, \mathrm{Br}, \mathrm{I})$ with $\mathrm{As}\left(\mathrm{SiMe}_{3}\right)_{3}$ or $\mathrm{P}\left(\mathrm{SiMe}_{3}\right)_{3}$, respectively. Other analogous chemical routes to indium pnictides have also appeared in the literature. ${ }^{112}$

GaAs nanocrystallites have been prepared by reacting $\mathrm{GaCl}_{3}$ with $\mathrm{As}\left(\mathrm{SiMe}_{3}\right)_{3}$ in boiling quinol ine; however, as yet unidentified species were found to mask the optical properties of the resulting particles, and hence quantum size effects could not be properly determined. ${ }^{113,114}$ The alcoholysis or thermolysis of silylated single molecule precursors is one of several processes used for nanoparticle synthesis of IIIN and IIN semiconductor materials. Another preparative method for the syntheses of $\mathrm{GaAs}^{115}$ and InP116 is by the methanolysis of organometallic compounds such as $[\mathrm{Cp} *(\mathrm{Cl}) \ln (\mu-\mathrm{P}(\mathrm{Si}-$ $\left.\left.\mathrm{Me}_{3}\right)_{2}\right]_{2}$. The chemical route, eq 21 , led ${ }^{117,118}$ to bulk, amorphous, $\mathrm{Cd}_{3} \mathrm{P}_{2}$ after rapid flocculation of $\mathrm{Cd}_{3} \mathrm{P}_{2}$ nanoparticles. To control the kinetics, a single molecule precursor with bulkier substituents was used, Cd$\left[\mathrm{P}\left(\mathrm{SiPh}_{3}\right)_{2}\right]_{2}$ (eq 22). ${ }^{118,119}$ The methanolysis gave soluble nanoparticles of $\mathrm{Cd}_{3} \mathrm{P}_{2}$ with diameters ranging from 30 to $40 \AA$; however, the particles were not crystalline.

Other chemical routes to metal phosphides include phosphinolysis reactions and reactions between metalloorganics and $\mathrm{P}\left(\mathrm{SiMe}_{3}\right)_{3}$; all involve elimination and condensation processes. Buhro ${ }^{118}$ reported the synthesis 
of several binary phosphide semiconductors al ong with ternary phases (e.g. $\mathrm{ZnGeP}_{2}$ ), using solution-phase metallo-organic routes. Table 2 presents a representative, although not an exhaustive, summary of synthetic methods for several nanocrystalline semiconductors.

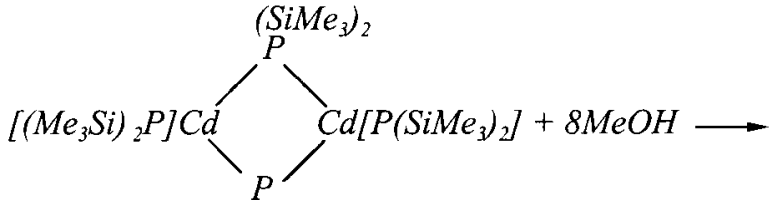

$\left(\mathrm{SiMe}_{3}\right)_{2}$

$$
2 / 3 \mathrm{Cd}_{3} \mathrm{P}_{2}+8 \mathrm{MeOSiMe}_{3}+8 / 3 \mathrm{PH}_{3}
$$

$$
\begin{aligned}
& \mathrm{Ph}_{3} \mathrm{Si} \backslash \mathrm{P}-\mathrm{Cd}-\mathrm{P} / \mathrm{PiPh}_{3}+4 / 3 \mathrm{MeOH} \rightarrow \\
& \mathrm{Ph}_{3} \mathrm{Si} / \mathrm{Sinh}_{\text {nano- } \mathrm{Cd}_{3} \mathrm{P}_{2}+4 / 3 \mathrm{HP}\left(\mathrm{SiPh}_{3}\right)_{2}+4 / 3 \mathrm{MeOSiPh}_{3}}
\end{aligned}
$$

\section{Processability}

One of the major goals in research on nanocrystallites is to make use of their unique properties in novel el ectronic devices. The production of any such devices will require the assembly and manipulation of semiconductor nanoparticles without loss of their unique properties. Nanoscale processes can be achieved using lithographic methods and/or scanning probe microscopy. ${ }^{150-152}$ A general chemical approach to the fabrication of nanostructured devices would be advantageous. To date the area is not well-developed, although there has been considerable progress in recent years. ${ }^{7}$ One promising method for the assembly of nanocrystallitebased devices is the use of Langmuir-Blodgett (LB) films. ${ }^{7,153,154}$ LB structures can be formed during the synthesis of inorganic nanocrystallites, and several examples have been reported. 7,136,137 Using an amphiphilic polymer, poly(maleic acid)octadecanol, and a cadmium or lead salt, ordered LB structures can be prepared and, when treated with $\mathrm{H}_{2} \mathrm{~S}$, result in $\mathrm{CdS}$ and $\mathrm{PbS}$ nanoparticle layers in an ordered organic matrix. ${ }^{130}$ A similar approach ${ }^{155}$ has been used in the preparation of films consisting of CdS nanostructures on a substrate. The substrate was obtained by the sel ective removal of a fatty acid matrix from LB films of cadmium arachidate, which were then exposed to $\mathrm{H}_{2} \mathrm{~S}$. Scanning tunneling microscopy images showed ${ }^{155}$ that the films consist of closely interconnected CdS particles. With the resulting particle dimensions depended on the initial number of cadmi um arachidate layers. It was suggested that a mechanism involving particle aggregation is responsible for film formation. Another report describes the synthesis of CdS using LB calyxarene and LB stearate, smaller particles $(1.5 \pm 0.3 \mathrm{~nm})$ were obtained when LB calyxarene films were used, although in this case the particle size appears independent both of the type of calyxarene used or the number of LB layers involved. 156

Nanostructures can also be prepared by the assembly of preformed nanocrystallites, as in the formation of molecular deposition (MD) films via electrostatic attractions between opposite-charged species. ${ }^{157}$ Figure 7 shows a schematic structure obtained by the assembly of anionic $\mathrm{Pbl}_{2}$ nanocrystallites using bi polar pyridinium salt as the cationic species. Self-assembled monolayers have been used to attach CdS nanocrystals to metal substrates via carboxylate or alkanedithiol mol ecules. ${ }^{158}$ The assembly of nanodispersed CdS or CdSe into a nanocomposite containing molecular bridging ligands, such as pyrazine or 2,2'-bipyrimidine, between particles give near band edge luminescence for the original nanocrystallites as well as when in the final composite. ${ }^{98}$

Most studies on surface modification of nanocrystals deal with effects associated with optical properties. Surface derivatization studies and their effects on other physical properties are needed. On the basis of el ectron diffraction studies, it was reported that, under ambient conditions, changes in the crystalline phase could occur in nanocrystalline ZnS. Moreover, depending on the coordinating molecules used to surface derivatize the particle (capping agent), a phase change within the particle can occur; thus, when $\mathrm{C}_{6} \mathrm{~F}_{5} \mathrm{SH}$ is used to surface derivatize hexagonal ZnS nanoparticles, a transition to cubic phase can occur. ${ }^{159}$

Other authors have used polymer molecules attached to the nanocrystallites surface to assemble nanoparticulates into larger structures. F or example $\mathrm{CdS}^{129}$ and $\mathrm{GaAs}^{123}$ particles embedded in poly(vinyl)alcohol film were obtained using a gas-aerosol reactive electrostatic deposition technique. The nanoparticles were initially obtained by the reaction of metal ions in the aerosol droplets, containing the polymer, with $\mathrm{H}_{2} \mathrm{~S}$ or arsine generated in situ. The semiconductor/polymer particles produced are driven under the electric field toward and subsequently deposited onto a substrate.

A sequential polymerization was used to prepare ZnS clusters of sizes up to $30 \AA, 140$ with the particle size depending mainly on the temperature and the strength of the polymer-particle interaction. Other molecular species such as Lewis bases can be used to bind to the surface of nanoparticulates, and by cross-linking a novel organic/inorganic structure can be obtained; this method has been used for $\mathrm{ZnS}^{138}$ and CdS particles. ${ }^{30,160,161}$

In favorable circumstances the synthesis and assembly of nanocrystallites can be achieved simultaneously; Kimizuka and Kunitake reported ${ }^{162}$ the use of superlattices to produce organized nanostructures using different methodologies. Figure 8 depicts the synthesis/ assembly scheme for $\mathrm{Cd}_{4} \mathrm{Br}_{12} \mathrm{~S}$ clusters in a bilayer ligand. ${ }^{162} \mathrm{CdBr}_{3}{ }^{-}$in the bilayer ligand is posttreated with $\mathrm{H}_{2} \mathrm{~S}$. This method is somewhat similar to that described by Wang and Herron for the preparation of CdS. ${ }^{69}$

Novel three-dimensional ordered structures have been obtained by the selective crystallization of capped CdSe/ TOPO nanocrystall ites dispersed in organic solvents. ${ }^{163}$ These structures were characterized by diffraction techniques and high-resolution el ectron mi croscopy and shown to consist of quantum dot superlattices. The optical properties displayed by macroscopic assemblies of nanostructered material depend on both the properties of the individual nanocrystallites and the interactions existing between them. There are still problems in understanding how nanoparticulate physical properties develop when a macrocrystalline material is built up from these smaller units. The synthesis and characterization of clusters having structural similarities to larger nanocrystallites ${ }^{164,165}$ may allow for an improved 
Table 2. Routes for the Preparation of Semiconductor Nanocrystallites

\begin{tabular}{|c|c|c|c|}
\hline semiconductor & synthetic method & particles size range/nm & refs \\
\hline Si (silica coated) & combustion of silane, followed by HF etching & $2-10$ & 57 \\
\hline \multirow[t]{3}{*}{$\mathrm{Ge}$} & $\begin{array}{l}\text { thermal treatment of a silica xerogel } \\
\text { doped with } \mathrm{Me} \mathrm{e}_{3} \mathrm{GeS}\left(\mathrm{CH}_{2}\right)_{3} \mathrm{Si}(\mathrm{OMe})_{3}\end{array}$ & 6.8 & 120 \\
\hline & $\begin{array}{l}\mathrm{nGeCl}_{4}+4 \mathrm{nLi}\left[\mathrm{C}_{10} \mathrm{H}_{8}\right] \text { in THF, followed by } \\
\text { laser illumination }\end{array}$ & $2-60$ & 55 \\
\hline & $\begin{array}{l}\text { ultrasonic reduction of germane derivatives in } \\
\text { the presence of } \mathrm{Na} / \mathrm{K} \text { alloy. }\end{array}$ & $6-20$ & 56 \\
\hline GaN & thermolysis of $\left[\mathrm{H}_{2} \mathrm{GaNH}_{2}\right]_{3}$ in supercritical ammonia & 3 & 121 \\
\hline \multirow[t]{2}{*}{$\mathrm{GaP}$} & $(\mathrm{Na} / \mathrm{K})_{3} \mathrm{As}+\mathrm{GaCl}_{3}$ in organic solvents & $11-21$ & 111 \\
\hline & $\begin{array}{l}\text { thermal treatment of }\left[\mathrm{C}_{12} \mathrm{GaP}\left(\mathrm{SiMe}_{3}\right)_{2}\right]_{2} \text { in a } \\
\text { TOPO + TOP mixture }\end{array}$ & $2-6.5$ & 122 \\
\hline \multirow[t]{4}{*}{ GaAs } & gas-aerosol reactive electrostatic deposition & $13-14$ & 123 \\
\hline & vapor-phase nucleation from organometallic precursors & $10-20$ & 124 \\
\hline & $(\mathrm{Na} / \mathrm{K})_{3} \mathrm{As}+\mathrm{GaCl}_{3}$ in organic solvents & $6-36$ & 111 \\
\hline & $\mathrm{GaCl}_{3}+\mathrm{As}\left[\mathrm{Si}\left(\mathrm{CH}_{3}\right)\right]_{3}$ in quinoline $\left(240{ }^{\circ} \mathrm{C}\right)$ & & 113 \\
\hline \multirow[t]{5}{*}{$\ln P$} & $\mathrm{InCl}_{3}+\mathrm{P}\left(\mathrm{Si}\left(\mathrm{CH}_{3}\right)_{3}\right)_{3}$ in hot TOPO & $2-5$ & 108 \\
\hline & $\begin{array}{l}\text { methanolysis of single molecule precursors } \\
\left(\text { e.g. }\left[\mathrm{R}_{2} \operatorname{lnP}\left(\mathrm{SiMe}_{3}\right)_{2}\right]_{2}\right.\end{array}$ & & 116 \\
\hline & phase solution reaction: $\operatorname{InX} X_{3}(X=\mathrm{Cl}, \mathrm{Br}, \mathrm{I})+\mathrm{P}\left[\mathrm{Si}\left(\mathrm{CH}_{3}\right)_{3}\right]$ & $2.5-4$ & 112 \\
\hline & MOCVD inside MCM-41 & $3.4-4.3$ & 125 \\
\hline & $\begin{array}{l}\text { thermal treatment of a chloroindium oxalate } \\
\text { complex }+\mathrm{P}\left(\mathrm{SiMe}_{3}\right)_{3} \text { in TOPO }+ \text { TOP mixture }\end{array}$ & $2-6.5$ & 122 \\
\hline \multirow[t]{2}{*}{ InAs } & $\mathrm{InCl}{ }_{3}+\mathrm{As}\left[\mathrm{Si}\left(\mathrm{CH}_{3}\right)_{3}\right]_{3}$ in TOP at $240-260^{\circ} \mathrm{C}$ & $2.5-6$ & 109 \\
\hline & phase solution reaction: $\operatorname{InX} X_{3}(\mathrm{X}=\mathrm{Cl}, \mathrm{Br}, \mathrm{I})+\mathrm{As}\left[\mathrm{Si}\left(\mathrm{CH}_{3}\right)_{3}\right]$ & $9-16$ & 112 \\
\hline \multirow[t]{3}{*}{$\mathrm{Cd}_{3} \mathrm{P}_{2}$} & thermolysis of $\left[\mathrm{MeCdP}^{\mathrm{t}} \mathrm{Bu}_{2}\right]_{3}$ in TOPO & & 126 \\
\hline & $\begin{array}{l}\text { treatment of aqueous } \mathrm{Cd}(\mathrm{II}) \text { with } \mathrm{PH}_{3} \text { in the } \\
\text { presence of }\left(\mathrm{NaPO}_{3}\right)_{6}\end{array}$ & $1-2$ & 44,52 \\
\hline & alcoholysis of $\mathrm{Cd}\left[\mathrm{P}\left(\mathrm{SiPh}_{3}\right)_{2}\right]_{2}$ & $3-4$ & 118,119 \\
\hline $\mathrm{Cd}_{3} \mathrm{As}_{2}$ & $\begin{array}{l}\text { treatment of aqueous } \mathrm{Cd}(\mathrm{II}) \text { with arsine in the } \\
\text { presence of }\left(\mathrm{NaPO}_{3}\right)_{6}\end{array}$ & & 127 \\
\hline \multirow[t]{2}{*}{$\mathrm{Zn}_{3} \mathrm{P}_{2}$} & $\begin{array}{l}\text { treatment of aqueous } \mathrm{Zn}(\mathrm{II}) \text { with } \mathrm{PH}_{3} \text { in the } \\
\text { presence of }\left(\mathrm{NaPO}_{3}\right)_{6}\end{array}$ & $1-2$ & 52 \\
\hline & alcoholysis of $\mathrm{Zn}\left[\mathrm{P}\left(\mathrm{SiPh}_{3}\right)_{2}\right]_{2}$ & $1.5-2.5$ & 118 \\
\hline \multirow[t]{17}{*}{ CdS } & $\begin{array}{l}\text { arrested precipitation within amphiphilic systems } \\
\text { (AOT) }\end{array}$ & $2-6$ & 77 \\
\hline & arrested precipitation in the presence of polyphosphates & $2-3.6$ & 48 \\
\hline & thermolysis of single molecule precursors in TOPO & $3-7$ & 98,128 \\
\hline & gas-aerosol reactive electrostatic deposition & 4.5 & 129 \\
\hline & growth inside zeolite pores & $<1.3$ & 69 \\
\hline & $\begin{array}{l}\text { exposure of Langmuir-Blodgett films containing } \\
\text { cadmium to HS }\end{array}$ & & 130 \\
\hline & $\begin{array}{l}\text { formation inside porous silica-pillared layered } \\
\text { metal(IV) phosphates }\end{array}$ & 2.5 & 70 \\
\hline & formation within polymer matrices using ionomers & $1.8-2.3$ & 86 \\
\hline & $\begin{array}{l}\text { treatment of a xerogel matrix (polysilsesquioxane) } \\
\text { with } \mathrm{Cd}^{2+} \text { and } \mathrm{S}^{2-}\end{array}$ & $6-9$ & 79 \\
\hline & hydrolysis of $\mathrm{P}_{2} \mathrm{~S}_{5}$ in an ethanol solution of $\mathrm{Cd}\left(\mathrm{NO}_{3}\right)_{2} \cdot 4 \mathrm{H}_{2} \mathrm{O}$ & $\leq 6$ & 131 \\
\hline & arrested precipitation in aqueous and methanolic media & $\overline{3}$ & 41 \\
\hline & $\begin{array}{l}\mathrm{CdSO}_{4}+\left(\mathrm{NH}_{4}\right)_{2} \mathrm{~S} \text { in aqueous/acetonitrile solutions } \\
\text { using copolymers as stabilizers }\end{array}$ & $2.1-7.5$ & 40 \\
\hline & arrested precipitation within surfacttant vesicles (DODAC) & $2.2-5$ & 74 \\
\hline & precipitation in nonaqueous solvents without added stabilizers & $2.2-3.8$ & 27 \\
\hline & $\mathrm{CdMe}_{2}+\left[\left(\mathrm{Me}_{3} \mathrm{Si}\right)_{2} \mathrm{~S}\right]$ in hot TOPO & $2-3$ & 32 \\
\hline & methatesis of $\mathrm{Cd}\left[\mathrm{N}\left(\mathrm{Me}_{3} \mathrm{Si}\right)_{2}\right]_{2}+\mathrm{SCNR}$ in the presence of TOPO & $1.5-2$ & 134 \\
\hline & solventothermal reaction of $\mathrm{CdC}_{2} \mathrm{O}_{4}+\mathrm{S}\left(120-180^{\circ} \mathrm{C}\right)$ & $20-60 \times 200-4800$ (rods) & 135 \\
\hline \multirow[t]{6}{*}{ CaSe } & solution-phase thermolysis of $\left[\mathrm{Cd}(\mathrm{SePh})_{2}\right]_{2}$ & 3 & 105 \\
\hline & thermolysis of single-molecule precursors in TOPO & $3-8$ & $97,98,128$ \\
\hline & $\begin{array}{l}\text { exposure of Langmuir-Blodgett films of cadmium } \\
\text { arachidate to } \mathrm{H}_{2} \mathrm{Se}\end{array}$ & $2.2-2.6$ & 136 \\
\hline & $\mathrm{CdMe}_{2}+(\mathrm{TOP})$ Se in hot TOPO & $1.2-11.5$ & 32,141 \\
\hline & $\begin{array}{l}\text { methatesis of } \mathrm{Cd}\left[\mathrm{N}\left(\mathrm{Me}_{3} \mathrm{Si}\right)_{2}\right]_{2}+\mathrm{SCNR} \text { in the presence } \\
\text { of TOPO }\end{array}$ & $1.5-2$ & 134 \\
\hline & solventothermal reaction of $\mathrm{CdC}_{2} \mathrm{O}_{4}+\mathrm{Se}\left(120-180^{\circ} \mathrm{C}\right)$ & $6-20 \times 100-500$ (rods) & 135 \\
\hline \multirow[t]{2}{*}{ CdTe } & $\mathrm{CdMe}_{2}+(\mathrm{TOP}) \mathrm{Te}$ in hot TOPO & $2-3$ & 32 \\
\hline & solventothermal reaction of $\mathrm{CdC}_{2} \mathrm{O}_{4}+\mathrm{Te}\left(120-180^{\circ} \mathrm{C}\right)$ & $20 \times 100-1000$ (rods) & 135 \\
\hline \multirow[t]{5}{*}{ ZnS } & solutions of polymeric aducts of zinc alkyls $+\mathrm{H}_{2} \mathrm{~S}$ & $2-4$ & 138 \\
\hline & arrested precipitation in aqueous and methanolic solutions & $<2$ & 41 \\
\hline & $\begin{array}{l}\text { photodegradation of } 3 \mathrm{~nm} \text { particles or precipitation } \\
\text { in phosphate containing solution }\end{array}$ & 1.7 & 139 \\
\hline & treatment of zinc containing copolymers with $\mathrm{H}_{2} \mathrm{~S}$ & $<3$ & 140 \\
\hline & thermolysis of single molecule precursors in TOPO & & 128 \\
\hline \multirow{4}{*}{$\begin{array}{l}\text { ZnSe } \\
\mathrm{PbS}\end{array}$} & thermolysis of single molecule precursors in TOPO & $3.5-4.2$ & 128 \\
\hline & growth inside zeolite pores & $<1.3$ & 69 \\
\hline & $\begin{array}{l}\text { exposure of LangmuirBlodgett films containing } \\
\text { lead(II) to } \mathrm{H}_{2} \mathrm{~S}\end{array}$ & & 130,133 \\
\hline & & & \\
\hline
\end{tabular}


Table 2 (Continued)

\begin{tabular}{|c|c|c|c|}
\hline semiconductor & synthetic method & particles size range/nm & refs \\
\hline $\mathrm{PbS}$ & $\begin{array}{l}\text { thermolysis of lead(II) dithiocarbamates in TOPO } \\
\text { growth within polymer matrices (ethylene-methacrylic acid) } \\
\text { arrested precipitation in the presence of poly }(\text { vinyl alcohol ) } \\
\text { treatment of lead(II) containing copolymers with } \mathrm{H}_{2} \mathrm{~S}\end{array}$ & $\begin{array}{l}6.3-20 \\
1.3-12.5 \\
2-3 \\
<2\end{array}$ & $\begin{array}{l}99 \\
82 \\
142 \\
85\end{array}$ \\
\hline $\mathrm{PbSe}$ & $\begin{array}{l}\text { treatment of acetonitrile/aqueous solutions of } \\
\qquad \mathrm{Pb}\left(\mathrm{CH}_{3} \mathrm{CO}_{2}\right)_{2} \text { with } \mathrm{H}_{2} \mathrm{Se} \text { in the presence of Nafion }\end{array}$ & $2-20$ & 143 \\
\hline $\mathrm{Cd}(\mathrm{OH})_{2} / \mathrm{CdS}$ & $\begin{array}{l}\text { arrested precipitation using aqueous }\left(\mathrm{NaPO}_{3}\right)_{6} \text { as } \\
\text { stabilizer, then an activation step using } \mathrm{NaOH} \text {. }\end{array}$ & $4-6$ & 29 \\
\hline $\mathrm{CdS} / \mathrm{SiO}_{2}$ & $\begin{array}{l}\text { hydrolysis of tetraethyl orthosilicate + coprecipitation } \\
\text { of CdS within water-in-oil-microemulsions }\end{array}$ & $40-300$ & 144,145 \\
\hline $\mathrm{CdS} / \mathrm{CdSe}$ & arrested precipitation using aqueous $\left(\mathrm{NaPO}_{3}\right)_{6}$ as stabilizer & $4-6$ & 146 \\
\hline $\mathrm{PbS} / \mathrm{CdS}$ & $\begin{array}{l}\text { arrested precipitation of CdS using poly(vinylpyrrolidone) } \\
\text { as stabilizer, then } \mathrm{Pb}^{2+} \text { displacing cadmium ions }\end{array}$ & $6-8$ & 61,62 \\
\hline ZnS/CdS & $\begin{array}{l}\text { arrested precipitation in the presence of } \\
\text { dihexadecyl phosphate vesicles }\end{array}$ & 4.6 & 147 \\
\hline $\mathrm{CdSe} / \mathrm{ZnS}$ & arrested precipitation within inverse micelles & 4.5 & 64 \\
\hline ZnSe/CdSe & $\begin{array}{l}\text { CdSe prepared from } \mathrm{CdMe}_{2}+\text { TOPSe in hot } \\
\text { TOPO, then organometallic chemical vapor } \\
\text { deposition using } \mathrm{H}_{2} \mathrm{Se} \text { and } \mathrm{ZnEt}_{2}\end{array}$ & $4-6.8$ & 148,149 \\
\hline $\mathrm{CdS} / \mathrm{HgS} / \mathrm{CdS}$ & $\begin{array}{l}\text { treatment of aqueous } \mathrm{Cd}\left(\mathrm{ClO}_{4}\right)_{2} \text { and } \mathrm{Hg}\left(\mathrm{ClO}_{4}\right)_{2} \\
\text { with } \mathrm{H}_{2} \mathrm{~S} \text { in the presence of } \mathrm{Na}_{6}\left(\mathrm{PO}_{3}\right)_{6}\end{array}$ & 8 & 67,68 \\
\hline GalnP 2 & $\begin{array}{l}\text { thermal treatment of chlorogallium oxalate }+ \\
\text { chloroindium oxalate }+\mathrm{P}\left(\mathrm{SiMe}_{3}\right)_{3} \text { in TOPO }\end{array}$ & 2.5 & 122 \\
\hline
\end{tabular}

understanding of the relationship between size and material properties.

Properties and Potential Applications. Bawendi et al. reported 148,149 the use of CdSe/TOPO nanocrystals in a thin film device, in which the wavelength of emission could betuned by selection of nanocrystal size. Nanocrystallites of CdSe were surface derivatized with pyridine and then grown into a semiconducting thin film, using el ectrospray organometallic chemical vapor deposition. Luminescence of the CdSe particles was enhanced if a ZnSe layer was used to further cover the surface. The maximum luminescence yield at room temperature detected for coated $\mathrm{CdSe} / \mathrm{ZnSe}{ }^{149}(\Phi \approx$ $0.4 \%)$ is lower than the yield for CdSe/TOPO $(\Phi \approx$ 10\%). ${ }^{32}$ The authors suggest that the luminescence yield could be increased if epitaxial growth of defect free ZnSe particles could be achieved. ${ }^{149}$

Metal-thiolate complexes are of interest since in the case of many compounds the structural framework is closely related to that of the corresponding metal sulfide

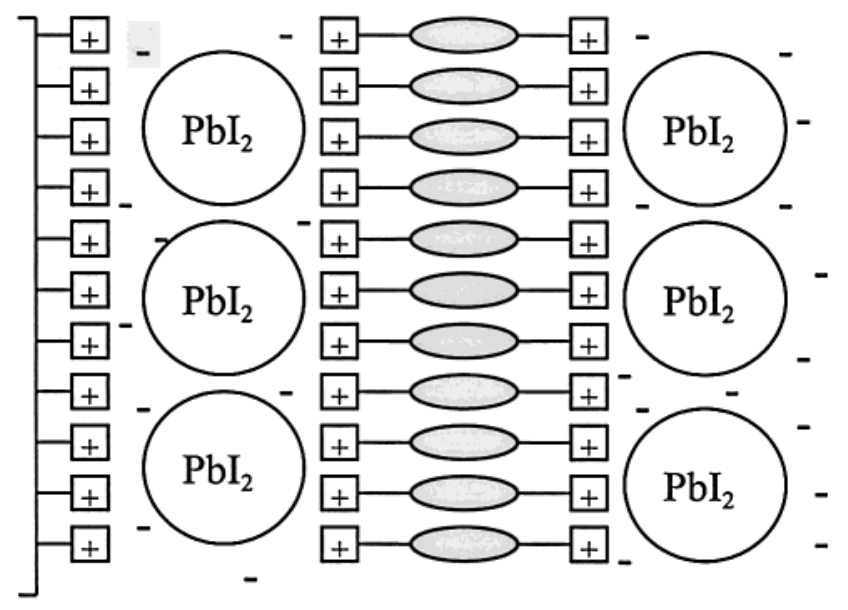

Bipolar pyridinium

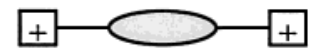

Figure 7. Proposed structure for multilayer alternating $\mathrm{Pbl}_{2}$ films prepared using a molecular deposition method. ${ }^{157}$ semiconductor. ${ }^{166}$ The synthesis and X-ray crystal structure of the cadmium sulfide cluster $\mathrm{Cd}_{17} \mathrm{~S}_{4}\left(\mathrm{SCH}_{2} \mathrm{CH}_{2-}\right.$ $\mathrm{OH})_{26}$ have been reported ${ }^{164}$ and can be described as a superlattice framework of two enlarged and interconnected (via covalent links) diamond lattices, Figure 9. The core of each cluster may be regarded as cubic phase CdS, with the capping cages having a structure similar to that of the hexagonal phase. The $\mathrm{Cd}-\mathrm{S}$ bond lengths in the core $(2.45-2.61 \AA)$ are in the same range as for bulk CdS (2.519 A). Optical spectra of solutions containing these clusters display very strong and sharp absorpti on bands at $290 \mathrm{~nm}$, which can be assigned to the first electronic transition within the cluster. In the crystalline solid the maximum is red shifted in the optical and luminescence spectra and is reported to reflect clustercluster interactions. ${ }^{164}$ Studies on the conversion of the molecular clusters, $\left(\mathrm{R}_{4} \mathrm{~N}^{+}\right)_{4}\left[\mathrm{~S}_{4} \mathrm{M}_{10}(\mathrm{SPh})_{16}\right]^{4-}(\mathrm{R}=\mathrm{Me}, \mathrm{Et}$; $M=C d, Z n)$, into bulk metal sulfide materials has been reported. ${ }^{167}$ Using a method based on heating the precursor under vacuum $\left(300^{\circ} \mathrm{C}\right)$, stable intermediate clusters of the type, $\mathrm{M}_{10} \mathrm{~S}_{16} \mathrm{Ph}_{12}$, are obtained and can be isolated by extraction using pyridine. F urther heating converts these intermediates into their respective metal sulfides.

Optoelectronic Applications. The large surface area of a nanocrystal and the surrounding medium, such as the capping agent, can have a profound effect on the properties of the particle. Defects within the particle act as electron/hole traps which can lead to nonlinear optic effects. ${ }^{22}$ New nonlinear composite materials can be prepared by either doping polymers or glasses with semiconductor nanocrystallites. ${ }^{138} \mathrm{H}$ erron et al. ${ }^{168}$ prepared polymer matrix composites containing PbS and CdS nanocrystallites and showed the optical nonlinearity of material containing $50 \AA$ sized CdS nanocrystals to be $-6.1 \times 10^{-7} \mathrm{~cm}^{2} \mathrm{~W}^{-1}$ at $480 \mathrm{~nm}$.

Langmuir-Blodgett monolayers of $\mathrm{CdE}(\mathrm{E}=\mathrm{S}$, Se)/ TOPO-capped nanocrystallites have been reported. 169 Alivisatos et al. ${ }^{170}$ used this type of particle (30-50 $\AA$ ) and semiconducting p-paraphenylene vinylene (PPV) to prepare films and hence fabricate a hybrid organicl inorganic electroluminescence device. The color of the 

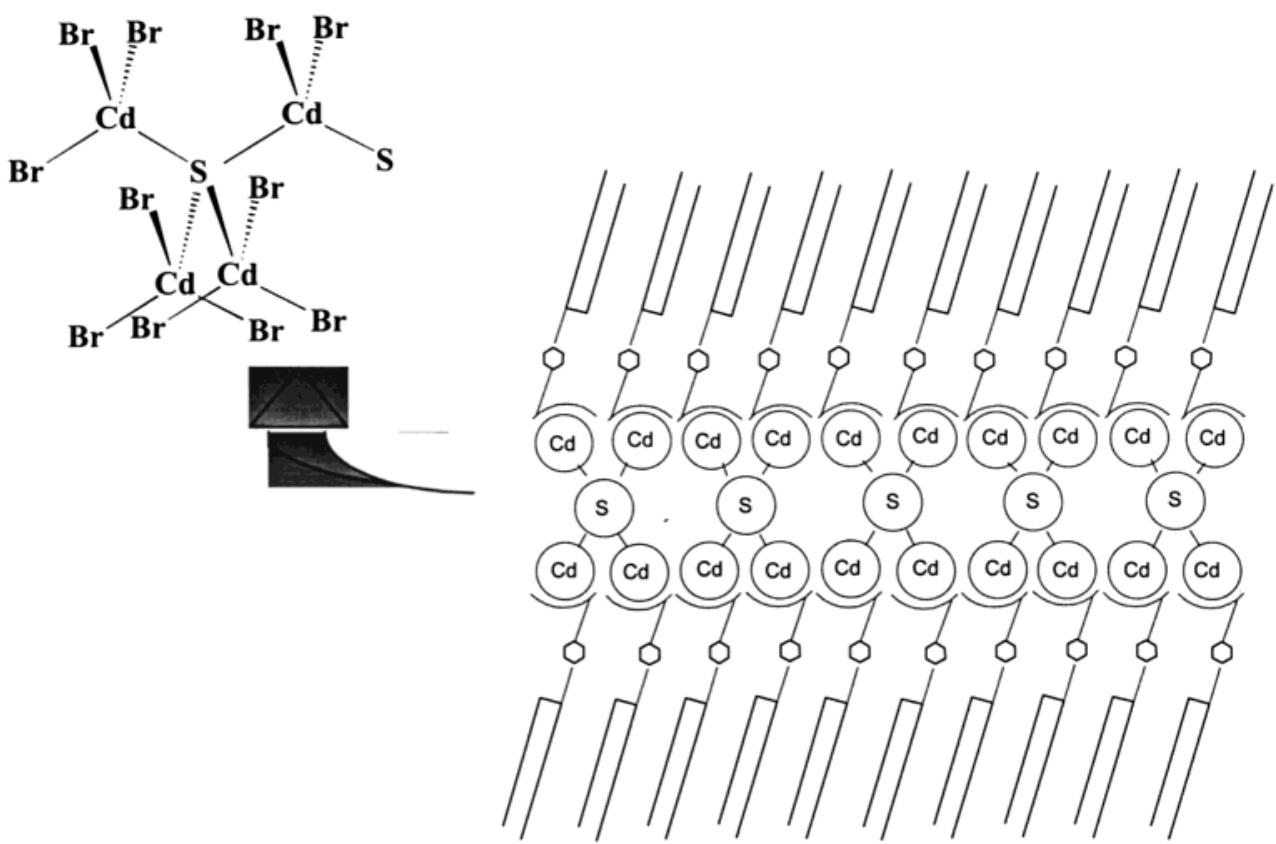

Figure 8. Synthesis/assembly scheme of $\mathrm{Cd}_{4} \mathrm{Br}_{12} \mathrm{~S}$ clusters in a bilayer ligand. ${ }^{162}$

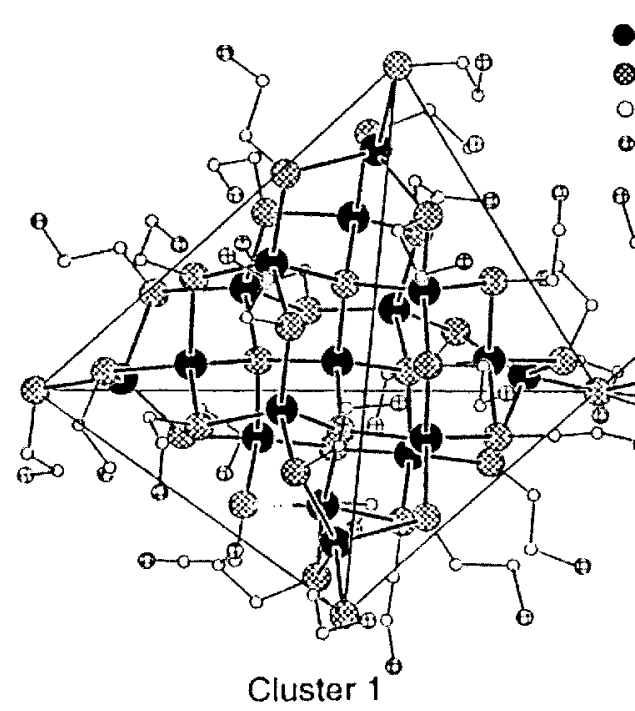

Figure 9. Superlattice built from $\mathrm{Cd}_{17} \mathrm{~S}_{4}\left(\mathrm{SCH}_{2} \mathrm{CH}_{2} \mathrm{OH}\right)_{26}{ }^{164}$

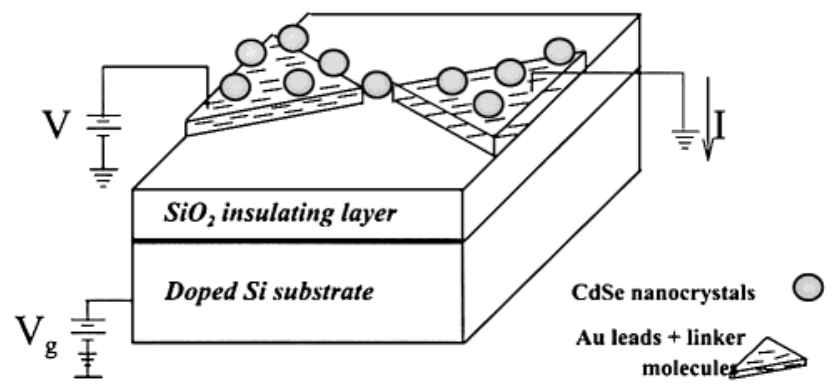

Figure 10. I dealized diagram of a single-electron transistor made from CdSe nanocrystals. ${ }^{171}$

emission varied from red to yellow by changing the size of the nanocrystals. More recently, devices fabricated from single nanocrystals have been proposed such as a single-electron transistor based on CdSe nanocrystals, deposited on a $\mathrm{SiO}_{2} / \mathrm{Si}$ substrate using alkanethiols as circuit wires, Figure 10. ${ }^{171}$
A design for a solid-state laser, based on the luminescence properties of metal chal cogenide quantum dots (CdSe, CdTe, ZnSe, ZnTe), in a host material such as poly(methyl methacrylate) has been described; ${ }^{172}$ the wavelength of the emitted light is determined by the size of the nanocrystal lites chosen. The el ectrochemical fabrication of cadmium chal cogeni de mi crodiode arrays was reported ${ }^{173}$ and featured a template of microcylinders in which was grown crystallites of CdSe and CdTe ranging from 200 to $300 \mathrm{~nm}$ in size.

Although bulk silicon has an indirect band gap, it has been shown that luminescence can occur in silicon nanocrystallites; this opens up a wide range of possible applications for the use of silicon nanocrystallites. ${ }^{53,54,174}$ Brus highlighted the idea that, if it is possible to prepare silicon with useful luminescence and optical gain properties, communication devices might be grown directly on a silicon chip. ${ }^{174}$

Bulk ZnS is an important phosphor and exhibits electroluminescent behavior, especially when doped 
with $\mathrm{Mn}^{2+}$. It is widely used in the electronic industry, for example in electronic displays (orange emission, $\lambda$ $\approx 585 \mathrm{~nm}$ ). The synthesis of ZnS nanoparticles containing spatial ly localized $\mathrm{Mn}^{2+}$ in an aqueous medium has been described by Murphy et al., 175 who reports the photophysical properties of both doped ZnS:Mn (interstitial $\mathrm{Mn}^{2+}$ ) and activated $\mathrm{ZnS}: \mathrm{Mn}$ (surface $\mathrm{Mn}^{2+}$ ) particles. The former showed both orange and blue emissions, corresponding to emissions observed in bulk ZnS, which do not depend on doping levels. Activated ZnS:Mn nanocrystallites exhibit mainly band edge luminescence (ca. $350 \mathrm{~nm}$ ), although the reported emission lifetimes are shorter than that of the bulk material. This work suggests that the fabrication of luminescent ZnS:Mn devices, with distinct optical properties, can be achieved using ZnS nanocrystallites possessing spatially localized $\mathrm{Mn}^{2+}{ }^{175}$ Recently Bawendi et al. suggested that conventional methods used to manganese-dope CdSe nanoparticles do not result in the successful incorporation of manganese into the nanoparticle, with the manganese more likely to end up either trapped in the matrix containing the sample, bound to the capping agent on the surface, adsorbed directly on the surface of the particles, or doped randomly within the inorganic lattice. They report successfully manganese doping CdSe nanoparticles using the specifically designed single source manganese/selenium-containing organometallic complex $\mathrm{Mn}_{2}(\mu \text {-SeMe })_{2}(\mathrm{CO})_{8}$, which upon synthesis gave various size particles of $\mathrm{Cd}_{1-x} \mathrm{Mn}_{x} \mathrm{Se}^{176}$

Catalysis and Chemical Sensors. Thelarge surface area-to-volume ratio, al ong with the ability to tune the band gap, by choice of particle size, means that nanodispersed semiconductors can be used as sensitizers and catalysts in photochemical reactions. 6,177,178 The redox levels of the conduction and valence bands are especially sensitive to size quantization effects; with charge carriers formed after light absorption migrating to the surface of the particles where they can reduce or oxi dize surface-bound chemical species. A number of studies on this type of chemistry have been reported, including the use of ZnS nanoparticles for the oxidation of alcohols and the reduction of $\mathrm{CO}_{2}$ to formic acid. ${ }^{177} \mathrm{Hydrogen}$ can be produced by illuminating aqueous colloids of PbSe (50 $\AA$ ) or HgSe (50 $\AA$ ) particles, a reaction not observed when bulk PbSe is used. ${ }^{143}$ Similarly, $\mathrm{CO}_{2}$ reduction to formic acid, from $\mathrm{CO}_{2}$-saturated aqueous solutions occurred in the presence of CdSe (50 $\AA$ ), whereas no reaction is observed if larger particles are used. ${ }^{143}$ Enhancements in photoredox chemistry result because quantum confinement on the semiconductor particles creates energy levels which can accommodate electrons from chemical species, which in turn have enhanced reduction potentials.6,143

Polyurea (PUA) films containing CdS or ZnS nanocrystals in 10\% propan-2-ol aqueous solutions generate hydrogen when photoirradiated. ${ }^{179}$ The ZnS-PUA composite showed photocatalytic activity greater than that of the analogous CdS-PUA; this has been rationalized on the basis of the increased reducing ability of the conduction band electrons in ZnS compared to that of CdS. ${ }^{179}$

Metal oxides and metal sulfide particles have also been used as catalysis in the photoinitiated polymerization of both vinylic monomers, using $\mathrm{CdS},{ }^{132}$ and the polymerization of methyl methacrylate, using $\mathrm{ZnO}{ }^{180}$ There has been great interest in the use of $\mathrm{TiO}_{2}$ nanoparticles as sensors, for the detection of $\mathrm{O}_{2}, \mathrm{NO}_{2}$, and organic molecules. The selectivity of the sensor depends on the method used to produce $\mathrm{TiO}_{2}$ nanoparticles, with the efficiency of the chemical sensor increasing as particle size decreases. ${ }^{181,182}$ Chemical routes to nanocrystalline metal oxides have previously been reviewed. ${ }^{37}$ The pyrolysis of volatile compounds, the flame hydrolysis process, or reaction of metal clusters under an oxygen atmosphere are well-established methods used to produce superfine powders for ceramic applications. ${ }^{183,184}$

Energy Conversion and Storage. Grätzel and coworkers reported the construction of a novel solar cell185,186 device, based on the sensitization of highly porous nanocrystalline $\mathrm{TiO}_{2}$ with organic dyes. Nanocrystallites were also used as an alternative to the dyes. ${ }^{5}$ The sensitization of nanoporous wide-band gap semiconductors such as $\mathrm{TiO}_{2}, \mathrm{ZnO}, \mathrm{SnO}_{2}, \mathrm{Nb}_{2} \mathrm{O}_{5}$, and $\mathrm{Ta}_{2} \mathrm{O}_{5}$ by narrower band gap semiconductors (e.g. nanocrystalline CdS) has been studied. ${ }^{187}$ The energy levels of the substrates can be varied by using different metal oxides. ${ }^{187}$

\section{Conclusions}

Although a wide range of synthetic methods are now available for quantum dots of semiconductors, it seems clear that there is still a major problem associated with the reproducible preparation of robust materials of the kind that will be needed for technological applications.

The three generic methods all have advantages, considering each in turn. Colloidal methods use low temperatures and could be compatible with coatings onto plastics and other soft substrates. In general terms the crystallinity of many materials prepared by modifications of aqueous synthesis is somewhat suspect. However, for certain materials, soft ones, this approach may be advantageous. The recent synthesis of the semimetal $\mathrm{HgTe}$ as a semiconductor at sizes of the order of nanometers may be an important example.188 This material and other "soft" ones may be better synthesized by low-temperature routes. Colloidal methods, although the first way in which nanodispersed materials were prepared, still have problems with reproducibility and instability. Reactions in confined spaces as provided by micelles or biological materials may be an interesting extension of this method.

An extension of the colloid area is the preparation of very large clusters, as initially pioneered by Dance ${ }^{166}$ and further developed by Weller. ${ }^{164}$ This approach overcomes the crystallinity problem inherent in classical colloid approaches by the formation of well-defined species such as $\left[\mathrm{Cd}_{10} \mathrm{~S}_{4}(\mathrm{SPh})_{16}\right]^{4-}$. However, the ultimate limits of this approach are yet to be defined. Work on larger clusters of this type really does start to question when does a solution of a compound become a sol derived from a colloid.

The use of higher temperature methods, typically using processing temperatures of the order of 200-300 ${ }^{\circ} \mathrm{C}$, may have intrinsic advantages and certainly at these temperatures good samples of CdSe are readily prepared by routes based on thermolysis in TOPO or related solvents. Several groups have been involved in 
devel oping such chemistry, it is interesting to note that Alivisatos ${ }^{95}$ prepared better quality CdSe when the temperature of injection was raised to $350^{\circ} \mathrm{C}$ in contrast to the lower temperatures originally used by Murray and Bawendi. ${ }^{32}$ In a sense, in this area, what has emerged is an organometallic and metal-organic approach to colloid synthesis. These routes are another example of a top-down approach to nanotechnology, producing well-defined materials often with astonishingly few defects in an organic matrix. For semiconductor materials the majority of simple prototypic devices have been made from material prepared by these methods. Nanoparticle materials can be made more robust by making core-shell structures, especially those in which a high band gap material confines a lower band gap one. 189,190 These methods also produce materials that can readily be blended with polymers.

The interplay between polymer chemistry and quantum dot synthesis will undoubtedly become more important. In a special example of confined reaction space synthesis, Cole-Hamilton and co-workers have developed functional ized polymers for the synthesis of CdSe. ${ }^{191}$ Chemical synthetic methods for the assembly of nanocrystals into composites, such as the recent report by Bawendi et al., on II-VI semiconductor quantum dotpolymer composite materials, ${ }^{192}$ represent an important step toward the fabrication of new functional devices.

It remains true today as in $1991^{22}$ that there are no general methods for the synthesis of defined robust materials. Chemical synthetic techniques provide wellestablished methods for the preparation of semiconductor nanocrystallites. The unique properties of these materials, especially the possibilities for band gap tailoring and tuned luminescence, may lead to their potential use in many future technologies.

Acknowledgment. T.T. acknowledges Fundação para a Ciência e Tecnologia (Portugal) for funding. P.O.B. thanks the EPSRC and BT for their support of studies on quantum dots, at ICSTM and at the University of Manchester. P.O.B. is the Sumitomo/STS visiting professor at ICSTM. We thank the Anglo-Portuguese J oint Research Program Treaty of Windsor for a travel grant enabling us to write this article and collaborate.

\section{References}

(1) Henglein, A. Chem Rev. 1989, 89, 1861.

(2) Steigerwald, M. L.; Brus, L. E. Acc. Chem. Res. 1990, 23, 183.

(3) Bawendi, M. G.; Steigerwald, M. L.; Brus, L. E. Annu. Rev. Phys. Chem. 1990, 41, 477.

(4) Weller, H. Angew. Chem., Int. Ed. Engl. 1993, 32, 41.

(5) Weller, H. Adv. Mater. 1993, 5, 88.

(6) Hagfeldt, A.; Grätzel, M. Chem. Rev. 1995, 95, 49

(7) Fendler, J . H.; Meldrum, F. C. Adv. Mater. 1995, 7, 607.

(8) Alivisatos, A. P. J . Phys. Chem. 1996, 100, 13226

(9) Stroscio, J . A.; Eigler, D. M. Science 1991, 254, 1319.

(10) Lieber, C. M.; Liu, J .; Sheehan, P. Angew. Chem., Int. Ed. Engl. 1996, 35, 687

(11) Berry, C. R. Phys. Rev. 1967, 161, 848

(12) Matijevic, E. Annu. Rev. Mater. Sci. 1985, 15, 483.

(13) Matijevic, E. Langmuir 1986, 2, 12.

(14) Pankove, J. I. Optical processes in semiconductors; Dover Publications Inc.: New York, 1970

(15) Haug, H.; Koch, S. W. Quantum theory of the optical and electronic properties of semi conductors; World Scientific Publishing Co. Pte. Ltd.: London, 1990; p 333.

(16) Brus, L. E. J . Chem. Phys. 1983, 79, 5566.

(17) Brus, L. E. J . Chem. Phys. 1984, 80, 4403

(18) Brus, L. J . Phys. Chem. 1986, 90, 2555.
(19) Weller, H.; Schmidt, H. M.; Koch, U.; Fojtik, A.; Baral, S.; Henglein, A.; Kunath, W.; Weiss, K.; Deiman, E. Chem. Phys. Lett. 1986, 124, 557.

(20) Schmidt, H. M.; Weller, H. Chem. Phys. Lett. 1986, 129, 615.

(21) Nosaka, Y.J. Phys. Chem. 1991, 95, 5054.

(22) Wang, Y.; Herron, N. J . Phys. Chem. 1991, 95, 525

(23) Lippens, P. E.; Lannoo, M. Phys. Rev. B 1989, 39, 10935

(24) Krishna, M. V. R.; Friesner, R. A. J . Chem. Phys. 1991, 95, 8309

(25) Wang, L.; Zunger, A. J . Phys. Chem. B 1998, 102, 6449.

(26) Vossmeyer, T.; Katsikas, L.; Giersig, M.; Popovic, I. G.; Diesner, K.; Chemseddine, A.; Eychmüller, A.; Weller, H. J . Phys. Chem. 1994, 98, 7665 .

(27) Chestnoy, N.; Harris, T. D.; Hull, R.; Brus, L. E.J . Phys. Chem 1986, 90, 3393

(28) Nirmal, M.; Dabbousi, B. O.; Bawendi, M. G.; Macklin, J J J Trautman, J. K.; Harris, T. D.; Brus, L. E. Nature 1996, 383, 802.

(29) Spanhel, L.; Haase, M.; Weller, H.; Henglein, A. J . Am. Chem. Soc. 1987, 109, 5649

(30) Noglik, H.; Pietro, W. J . Chem. Mater. 1994, 6, 1593.

(31) Peng, X.; Wilson, T. E.; Alivisatos, A. P.; Schultz, P. G. Angew. Chem. Int. Ed. Engl. 1997, 36, 145.

(32) Murray, C. B.; Norris, D. J .; Bawendi, M. G. J . Am. Chem. Soc 1993, 115, 8706.

(33) Henglein, A.; Mulvaney, P.; Linnert, T. Faraday Discuss. 1991, $92,31$.

(34) Reetz, M. T.; Helbig, W. J . Am. Chem. Soc. 1994, 116, 7401.

(35) Brust, M.; Fink, J .; Bethel, D.; Schiffrin, D. J .; Kiely, C. J . Chem. Soc., Chem. Commun. 1995, 1655.

(36) Tanori, J .; Pileni, M. P. Adv. Mater. 1995, 7, 862.

(37) Andrievskii, R. A. Russ. Chem. Rev. 1994, 63, 411.

(38) Hunter, R. J. Introduction to modern colloid science; Oxford University Press: Oxford, U.K., 1993.

(39) Wilhel my, D. M.; Matijevic, E. J . Chem. Soc., Faraday Trans. 1 $1984,80,563$

(40) Rossetti, R.; Ellison, J . L.; Gibson, J . M.; Brus, L. E. J . Chem Phys. 1984, 80, 4464

(41) Rossetti, R.; Hull, R.; Gibson, J . M.; Brus, L. E. J . Chem. Phys. 1985, 82, 552.

(42) Henglein, A. Pure Appl. Chem. 1984, 56, 1215.

(43) Duonghong, D.; Ramsdenl J .; Grätzel, M. J. Am. Chem. Soc $1982,104,2977$.

(44) Baral, S.; Fojtik, A.; Weller, H.; Henglein, A. J . Am. Chem. Soc. 1986, 108, 375

(45) Fischer, C. H.; Lilie, J .; Weller, H.; Katsikas, L.; Henglein, A. Ber. Bunsen-Ges. Phys. Chem. 1989, 93, 61.

(46) Fisher, C. H.; Weller, H.; Katsikas, L.; Henglein, A. Langmuir 1989, 5, 429.

(47) Eychmuller, A.; Katsikas, L.; Weller, H. Langmuir 1990, 6, 1605.

(48) Fojtik, A.; Weller, H.; Koch, U.; Henglein, A. Ber. Bunsen-Ges. Phys. Chem. 1984, 88, 969.

(49) Boxall, C.; Kelsall, G. H. J . Chem. Soc., Faraday Trans. 1991, 87, 3537.

(50) Boxall, C.; Kelsall, G. H. J . Chem. Soc., Faraday Trans. 1991 $87,3547$.

(51) Boxall, C. Chem. Soc. Rev. 1994, 137.

(52) Weller, H.; Fojtik, A.; Henglein, A. Chem. Phys. Lett. 1985, 117, 485.

(53) Wilson, W. L.; Szajowski, P. F.; Brus, L. E. Science 1993, 262 1242.

(54) Pavesi, L.; Dal Negro, L.; Mazzoleni, C.; Franzo, G.; Priolo, F. Nature 2000, 408, 440.

(55) Kornowski, A.; Giersig, M.; Vogel, M.; Chemseddine, A.; Weller H. Adv. Mater. 1993, 5, 634.

(56) Heath, J. R.; Shiang, J . J .; Alivisatos, A. P. J . Chem. Phys. 1994, 101,1607

(57) Fojtik, A.; Henglein, A. Chem. Phys. Lett. 1994, 221, 363.

(58) Zhang L.; Coffer, J . L.; Xu, W.; Zerda, T. W. Chem. Mater. 1997 9, 2249.

(59) Spanhel, L.; Henglein, A.; Weller, H. Ber. Bunsen-Ges. Phys. Chem. 1987, 91, 1359.

(60) Hässelbarth, A.; Eychmuller, A.; Eichberger, R.; Giersi, M.; Mews, A.; Weller, H. J . Phys. Chem. 1993, 97, 5333.

(61) Zhou, H. S.; Honma, I.; Komiyama, H.; Haus, J. W. J . Phys. Chem. 1993, 97, 895

(62) Zhou, H. S.; Sasahara, H.; Honma, I.; Komiyama, H.; Haus, J W. Chem. Mater. 1994, 6, 1534.

(63) Eychmüller, A.; Hässel barth, A.; Weller, H. J . Lumin. 1992, 53 , 113.

(64) Kortan, A. R.; Hull, R.; Opila, R. L.; Bawendi, M. G.; Steigerwald, M. L.; Carrol, P. J .; Brus, L. E. J . Am. Chem. Soc. 1990, 112, 1327.

(65) Hoener, C. F.; Allan, K. A.; Bard, A. J .; Campion, A.; Fox, M A.; Mallouk, T. E.; Webber, S. E.; White, J. M. J . Phys. Chem. 1992, 96, 3812

(66) Talapin, D. V.; Rogach, A. L.; Kornowski, A.; Haase, M.; Weller, H. Nano. Lett. 2001, 1, 207.

(67) Eychmüller, A.; Mews, A.; Weller, H. Chem. Phys. Lett. 1993 208, 59. 
(68) Mews, A.; Eychmuller, A.; Giersig, M.; Schooss, D.; Weller, H. J. Phys. Chem. 1994, 98, 934

(69) Wang, Y.; Herron, N. J . Phys. Chem. 1987, 91, 257.

(70) Cassagneau, T.; Hix, G. B.; J ones, D. J .; Maireles-Torres, P.; Rhomari, M.; Roziere, J. J . Mater. Chem. 1994, 4, 189.

(71) Abe, T.; Tachibana, Y.; Uematsu, T.; I wamoto, M. J . Chem. Soc. Chem. Commun. 1995, 1617.

(72) Brenchley, M. E.; Weller, M. T. Angew. Chem., Int. Ed. Engl 1993, 32, 1663.

(73) Blasse, G.;. Dirksen, C.J .; Brenchley, M. E.; Weller, M. T. Chem. Phys. Lett. 1995, 234, 177.

(74) Watzke, H. J .; Fendler, J . H. J . Phys. Chem. 1987, 91, 854

(75) Petit, C.; J ain, T. K.; Billoudet, F.; Pileni, M. P. Langmuir, 1994, 10,4446 .

(76) Khan-Lodhi, A.; Robinson, B. H.; Towey, T.; Herrmann, C. Knoche, W.; Thesing, U. In The Structure, dynamics and equilibrium properties of colloidal systems; Bloor D. M., WynJ ones E., Eds.; London; 1990; p 373.

(77) Towey, T. F.; Khan-Lodi, A.; Robinson, B. H. J . Chem. Soc., Faraday Trans. 1990, 86, 3757.

(78) Korgel, B. A.; Monbouquette, G. J . Phys. Chem. 1996, 100, 346.

(79) Choi, K. M.; Shea, K. J.J . Phys. Chem. 1994, 98, 3207.

(80) Choi, K. M.; Shea, K. J .J . Am. Chem. Soc. 1994, 116, 9052.

(81) Carpenter, J . P.; Lukehart, C. M.; Stock, S. R.; Wittig, J . E. Chem. Mater. 1995, 7, 201.

(82) Wang, Y.; Suna, A.; Mahler, W.; Kasowski, R. J . Chem. Phys. 1987, 87, 7315.

(83) Gao, M.; Yang, Y.; Yang, B.; Bian, F.; Shen, J . J . Chem. Soc., Chem. Commun. 1994, 2779.

(84) Nirmal, M., Murray, C. B.; Bawendi, M. G. Phys. Rev. B 1994, $50,2293$.

(85) Tassoni, R.; Schrock, R. R. Chem. Mater. 1994, 6, 744.

(86) Moffitt, M.; Eisenberg, A. Chem. Mater. 1995, 7, 1178.

(87) Shinojima, H.; Yumoto, J.; U esugi, N.; Omi, S.; Asahara, Y. Appl Phys. Lett. 1989, 55, 1519.

(88) Steigerwald, M. L.; Alivisatos, A. P.; Gibson, J. M.; Harris, T. D.; Kortan, A. R.; Muller, A. J .; Thayer, A. M.; Duncan, T. M.; Douglass, D. C.; Brus, L. E. J . Am. Chem. Soc. 1988, 110, 3046.

(89) Stuczynski, S. M.; Brennan, J . G.; Steigerwald, M. L. Inorg Chem. 1989, 28, 4431.

(90) Thayer, A. M.; Steigerwald, M. L.; Duncan, T. M.; Douglass, D. C. Phys. Rev. Lett. 1988, 60, 2673.

(91) Wong, K. K. W.; Mann, S. Adv. Mater. 1996, 8, 928.

(92) Mackle, P.; Charnock, J . M.; Garner, C. D.; Meldrum, F. C.; Mann, S. J. Am. Chem. Soc. 1993, 115, 8471.

(93) Meldrum, F. C.; Heywood, B. R.; Mann, S. Science 1992, 257

(94) Becerra, L. R.; Murray, C. B.; Griffin, R. G.; Bawendi, M. G. J . Chem. Phys. 1994, 100, 3297.

(95) Bowen Katari, J . E.; Colvin, V. L.; Alivisatos, A. P. J . Phys. Chem. 1994, 98, 4109.

(96) Mews, A.; Kadavanich, A. V.; Banin, U.; Alivisatos, A. P. Phys Rev. B 1996, 53, 13242

(97) Trindade, T.; O'Brien, P. Adv. Mater. 1996, 8, 161.

(98) Trindade, T.; O'Brien, P.; Zhang, X. Chem. Mater. 1997, 9, 523.

(99) Trindade, T.; O'Brien, P.; Zhang, X.; Motevalli, M. J . Mater Chem. 1997, 7, 1011.

(100) Trindade, T.; Monteiro, O. C.; O'Brien, P.; Motevalli, M. Polyhedron 1999, 18, 1171.

(101) O'Brien, P. In Inorganic Materials; 2nd ed.; Bruce, W., O'H are D., Eds.; Wiley \& Sons, 1996; p 525.

(102) Cowley, A. H.; J ones, R. A. Polyhedron 1994, 13, 1149.

(103) Bradley, D. C. Polyhedron 1994, 13, 1111.

(104) O'Brien, P.; Nomura, R. J . Mater. Chem. 1995, 5, 1761

(105) Brennan, J . G.; Siegrist, T.; Carrol, P.J .; Stuczynski, S. M.; Brus, L. E.; Steigerwald, M. J . Am. Chem. Soc. 1989, 111, 4141.

(106) Trindade, T.; O'Brien, P. J . Mater. Chem. 1996, 6, 343.

(107) Green, M.; O'Brien, P. Adv. Mater. Opt. Electron. 1997, 7, 277.

(108) Guzelian, A. A.; Katari, J . E. B.; Kadavanich, A. V.; Banin, U.; Hamad, K. I uban, E.; Alivisatos, A, P. Wolters, R. H.; Arnold C. C.; Heath, J. R. J . Phys. Chem. 1996, 100, 7212.

(109) Guzelian, A. A.; Banin, U.; Kadavanich, A. V.; Peng, X.; Alivisatos, A. P. Appl. Phys. Lett. 1996, 69, 1432.

(110) Treece, R. E.; Macala, G. S.; Rao, L.; Franke, D.; Eckert, H.; Kaner, R. B. I norg. Chem. 1993, 32, 2745.

(111) Kher, S. S.; Wells, R. L. Chem. Mater. 1994, 6, 2056.

(112) Wells, R. L.; Aubuchon, S. R.; Kher, S. S.; Lube, M. S.; White, P. Chem. Mater. 1995, 7, 793.

(113) Olshavsky, M. A.; Goldstein, A. N.; Alivisatos, A. P. J . Am. Chem. Soc. 1990, 112, 9438.

(114) Uchida, H.; Curtis, C. J .; Nozik, A. J . J . Phys. Chem. 1991, 95, 5382

(115) Byrne, E. K.; Parkanyi, L. K.; Theopold, H. Science 1988, 241

(116) Douglas, T.; Teopold, K. H. Inorg. Chem. 1991, 30, 594.

(117) Goel, S. C.; Chiang, M. Y.; Buhro, W. E. J . Am. Chem. Soc. 1990 $112,5636$.

(118) Buhro, W. E. Polyhedron 1994, 13, 1131.
(119) Matchett, M. A.; Viano, A. M.; Adolphi, N. L.; Stoddard, R. D. Buhro, W. E.; Conradi, M. S.; Gibbons, P. C. Chem. Mater. 1992, 4, 508.

(120) Carpenter, J . P.; Lukehart, C. M.; Henderson, D. O.; Mu, R.; J ones, B. D.; Glosser, R.; Stock, S. R.; Wittig, J . E.; Zhu, J . G. Chem. Mater. 1996, 8, 1268.

(121) J egier, J . A.; McKernan, S.; Gladfelter, W. L. Chem. Mater. 1998 10,2041

(122) Micic, O. I.; Sprague, J . R.; Curtis, C.J .; J ones, K. M.; Machol J . L.; Nozic, A.; Giessen, J . H.; Fluegel, B.; Mohs, G.; Peyghambarian, N. J. Phys. Chem. 1995, 99, 7754.

(123) Salata, O. V.; Dobson, P. J .; Hull, P. J .; Hutchison, J . L. Appl. Phys. Lett. 1994, 65, 189.

(124) Sercel, P. C.; Saunders: W. A.; Atwater, H. A.; Vahala, K. J ." Flagan, R. C. Appl. Phys. Lett. 1992, 61, 696.

(125) Agger, J. R.; Anderson, M. W.; Pemble, M. E.; Terasaki, O.; Nozue, Y.J. Phys. Chem. B 1998, 102, 3345

(126) Green, M.; O'Brien, P. Adv. Mater. 1998, 10, 527. Green, M. O'Brien, P. J . Mater. Chem. 1999, 9, 243.

(127) Fojtik, A.; Weller, H.; Henglein, A. Chem. Phys. Lett. 1985, 120, 552.

(128) Ludolph, B.; Malik, M. A.; O’Brien, P.; Revaprasadu, N. Chem. Commun. 1998, 1849.

(129) Salata, O. V.; Dobson, P. J .; Hull, P. J .; Hutchison, J . L. Thin Solid Films 1994, 251, 1.

(130) Peng, X.; Lu, R.; Zhao, Y. Y.; Qu, L.; Li, T. J . Phys. Chem. 1994 $98,7052$.

(131) Ohtaki, M.; Oda, K.; Eguchi, K.; Arai, H. Chem. Commun. 1996 1209.

(132) Hoffman, A. J .; Mills, G.; Yee, H.; Hoffmann, M. R. J . Phys Chem. 1992, 96, 5546

(133) Pan, Z. Y.; Shen, G.J .; Zhang, L. G.; Lu, Z. H.; Liu, J . Z. J . Mater. Chem. 1997, 7, 531.

(134) Babcock, J. R.; Zehner, R. W.; Sita, L. R. Chem. Mater. 1998 10,2027

(135) Yu, S.; Wu, Y.; Yang, J .; Han, Z.; Xie, Y.; Qian, Y.; Liu, X. Chem. Mater. 1998, 10, 2309.

(136) Urquart, R. S.; Furlong, D. N.; Gengenbach, T.; Geddes, N. J .; Grieser, F. Langmuir 1995, 11, 1127.

(137) Grieser, F.; Furlong, N. F.; Scoberg, D.; Ichinose, I.; Kimizuka, N.; Kunitake, T. J. Chem. Soc., F araday Trans. 1992, 88, 2207

(138) Li, X.; Fryer, J . R.; Cole-Hamilton, D. J . Chem. Commun. 1994 1715.

(139) Weller, H.; Koch, U.; Gutierrez, M.; Henglein, A. Ber. BunsenGes. Phys. Chem. 1984, 88, 649.

(140) Sankaran, V.; Yue, J .; Cohen, R. E.; Schrock, R. R.; Silbey, R. J Chem. Mater. 1993, 5, 1133.

(141) Dabbousi, B. O.; Bawendi, M. G.; Onitsuka, O.; Rubner, M. F Appl. Phys. Lett. 1995, 66, 1316.

(142) Gallardo, S.; Gutierrez, M.; Henglein, A.; J anata, E. Ber. BunsenGes. Phys. Chem. 1989, 93, 1080.

(143) Nedeljković, J . M.; Nenadović, M. T.; Mićić, O. I.; Nozik, A. J .J Phys. Chem. 1986, 90, 12

(144) Chang, S.; Liu, L.; Asher, S. A. J . Am. Chem. Soc. 1994, 116, 6739.

(145) Chang, S.; Liu, L.; Asher, S. A. J . Am. Chem. Soc. 1994, 116, 6745.

(146) Tian, Y.; Newton, T.; Kotov, N. A.; Guldi, D. M.; Fendler, J . H J. Phys. Chem. 1996, 100, 8927

(147) Youn, H. C.; Baral, S.; Fendler, J . H. J . Phys. Chem. 1988, 92, 6320.

(148) Danek, M.; J ensen, K. F.; Murray, C. B.; Bawendi, M. G. J . Cryst. Growth 1994, 145, 714.

(149) Danek, M.; J ensen, K. F.; Murray, C. B.; Bawendi, M. G. Chem Mater. 1996, 8, 173.

(150) Turton, R. Thequantum do; W. H. Freeman: Oxford, U.K., 1995

(151) Reed, M. A. Sci. Am. 1993, 268, 98

(152) Miyake, M.; Matsumoto, H.; Nishizawa, M.; Sakata, T.; Hirotaro, M.; Susumu, K.; Yoneyama, H. Langmuir, 1997, 13, 742.

(153) Scoberg, D. J .; Grieser, F.; F urlong, D. N. J . Chem. Soc., Chem. Commun. 1991, 515

(154) Kotov, N. A.; Meldrum, F. C.; Wu, C.; Fendler, J . H. J . Phys. Chem. 1994, 98, 2735.

(155) Facci, P.; Erokhin, V.; Tronin, A.; Nicolini, C. J . Phys. Chem 1994, 98, 13323.

(156) Nabok, A. V.; Richardson, T.; Davis, F.; Stirling, C. J. M. Langmuir 1997, 13, 3198

(157) Gao, M.; Gao, M.; Zhang, X.; Yang, Y.; Yang, B.; Shen, J J J Chem. Soc., Chem. Commun. 1994, 2777.

(158) Colvin, V. L.; Goldstein, A. N.; Alivisatos, A. P. J . Am. Chem. Soc. 1992, 114, 5221.

(159) Murakoshi, K.: Hosokawa, H.: Tanaka, N.: Saito, M.; Wada, Y Sakata, T.; Mori, H.; Yanagida, S. Chem. Commun. 1998, 321.

(160) Noglik, H.; Pietro, W. J. Chem. Mater. 1995, 7, 1333.

(161) Veinot, J . G. C.; Ginzburg, M.; Pietro, W. J . Chem. Mater. 1997 9, 2117.

(162) Kimizuka, N.; Kunitake, T. Adv. Mater. 1996, 8, 89.

(163) Murray, C. B.; Kagan, C. R.; Bawendi, M. G. Science 1995, 270 1335. 
(164) Vossmeyer, T.; Reck, G.; Katsikas, L.; Haupt, E. T. K.; Schulz, B.; Weller, H. Science 1995, 267, 1476.

(165) Herron, N.; Calabrese, J . C.; Farneth, W. E.; Wang, Y. Science 1993, 259, 1426

(166) Dance, I. G. Polyhedron 1986, 5, 1037.

(167) Farneth, W. E.; Herron, N.; Wang, Y. Chem. Mater. 1992, 4, 916.

(168) Wang, Y.; Herron, N.; Mahler, W.; Suna, A. J . Opt. Soc. Am. B $1989,6,808$.

(169) Dabbousi, B. O.; Murray, C. B.; Rubner, M. F.; Bawendi, M. G. Chem. Mater. 1994, 6, 216; Ferreira, P. M. S.; Timmons, A. B. Neves, M. C.; Dynarowicz, P.; Trindade, T. Thin Solid Films 2001, 389, 272.

(170) Colvin, V. L.; Schlamp, M. C.; Alivisatos, A. P. Nature 1994, 370, 354.

(171) Weller, H. Angew. Chem., Int. Ed. 1998, 37, 1658; Klein, D. L. Roth, R.; Lim, A. K. L.; Alivisatos, A. P.; McEuen, P. L. Nature, 1997, 389, 699 .

(172) Hakimi, F.; Bawendi, M. G.; Tumminelli, R.; Haavisto, J . R. U.S. Patent 5, 260, 957, 1993

(173) Klein, J. D.; Herrick, R. D.; Palmer, D.; Sailor, M.J .; Brumlik, C. J .; Martin, C. R. Chem. Mater. 1993, 5, 902.

(174) Brus, L. J . Phys. Chem. 1994, 98, 3575

(175) Sooklal, K.; Cullum, B. S.; Angel, S. M.; Murphy, C. J . J . Phys. Chem. 1996, 100, 4551

(176) Mikulec, F. V.; Kuno, M.; Bennati, M.; Hall, D. A.; Griffin, R. G.; Bawendi, M. G. J. Am. Chem. Soc. 2000, 122, 2532.

(177) Henglein, A.; Gutierrez, M.; Fisher, Ch. H. Ber. Bunsen-Ges. Phys. Chem. 1984, 88, 170.

(178) Henglein, A.; Fojtik, A.; Weller, H. Ber. Bunsen-Ges. Phys. Chem. 1987, 91, 441 .
(179) Shiojiri, S.; Hirai, T.; Komasawa, I. Chem. Commun. 1998, 1439.

(180) Hoffman, A.J .; Yee, H.; Mills, G.; Hoffman, M. R. J . Phys. Chem. 1992, 96, 5540.

(181) Kumar, K. N. P.; Keizer, K.; Burggraaf, A. J ; Okubo, T.; Nagamoto, H.; Morooka, S. Nature 1992, 358, 48.

(182) Sberveglieri, G.; Depero, L. E.; Ferroni, M.; Guidi, V.; Martinelli, G.; N elli, P.; Perego, C.; Sangaletti, L. Adv. Mater. 1996, 8, 334.

(183) Kriechbaum, G. W.; Kleinschmit, P. Angew. Chem., Int. Ed. Engl $1989,28,1416$.

(184) Siegel, R. W. Sci. Am. 1996, 275, 42

(185) Borgarello, E.; Kiwi, J :; Pelizzetti, E.; Visca, M.; Grätzel, M. Nature 1981, 289, 158

(186) O'Regan, B.; Moser, J .; Anderson, M.; Grätzel, M.J . Phys. Chem $1990,94,8720$

(187) Vogel, R.; Hoyer, P.; Weller, H. J . Phys. Chem. 1994, 98, 3183.

(188) Rogach, A.; Kershaw, S.; Burt, M.; Harrison, M.; Kornowski, A.; Eychmüller, A.; Weller, H. Adv. Mater. 1999, 11, 552.

(189) Dabbousi, B. O.; Rodriguez-Viejo, J .; Mikulec, F. V.; Heine, J. R.; Mattoussi, H.; Ober, R.; J ensen, K. F.; Bawendi, M. G. J. Phys. Chem. B 1997, 101, 9463.

(190) Revaprasadu, N.; Malik, M. A.; O'Brien, P.; Wakefield, G. Chem. Commun. 1999, 1573.

(191) Haggata, S. W.; Cole-Hamiltion, D. J .; Fryer, J . R., J . Mater. Chem. 1996, 6, 1771.

(192) Lee, J .; Sundar, V. C.; Heine, J . R.; Bawendi, M. G.; J ensen, K. F. Adv. Mater. 2000, 12, 1103 .

CM 000843P 